\title{
Beliefs about Whether Spending Implies Wealth
}

HEATHER BARRY KAPPES

JOE J. GLADSTONE

HAL E. HERSHFIELD

Forthcoming, Journal of Consumer Research 
Heather Barry Kappes (corresponding author) is Assistant Professor of Marketing in the Department of Management at The London School of Economics and Political Science (LSE), Houghton Street, London, WC2A 2AE, Tel: +44 (0)20 7107 5418, H.Kappes@1se.ac.uk. Joe J. Gladstone is Assistant Professor of Marketing at University of Colorado Boulder, Leeds School of Business, 995 Regent Dr, Boulder, CO 80309, Tel: +1 (303) 492-1811, Joe.Gladstone@Colorado.edu. Hal E. Hershfield is Associate Professor of Marketing and Behavioral Decision Making at the University of California, Los Angeles, Anderson School of Management, 110 Westwood Plaza, Los Angeles, CA, 90095, Tel: +1(310) 206-7814, Hal.Hershfield@anderson@ucla.edu. The authors thank Jonathan Berman, Mark FentonO’Creevy, Zoe Rahwan, Shoshana Dobrow Riza, Tara Reich, Abigail Sussman, Severine Toussaert, and Stephanie Tully for their helpful feedback on earlier drafts, and thank Kaitlin Rodwell, Nathan Susser, Henry Barklam, Tien Nguyen, and Fah Sriwannnavit for their help conducting the studies. Materials and data are available at https://osf.io/ch5wm/. Supplementary materials are included in the web appendix accompanying the online version of this article.

\section{Running Head: KAPPES, GLADSTONE, AND HERSHFIELD}

Editor: J. Jeffrey Inman

Associate Editor: Ashwani Monga 
Spending is influenced by many factors. One that has received little attention is the meaning that people give to the act of spending. Spending money might imply that someone is relatively wealthy — since they have money to spend - or relatively poor-since spending can deplete assets. We show that people differ in the extent to which they believe that spending implies wealth (SIW beliefs). We develop a scale to measure these beliefs and find that people who more strongly believe that spending implies wealth spend their own money relatively lavishly and are, on average, more financially vulnerable. We find correlational evidence for these relationships using objective financial-transaction data, including over 2 million transaction records from the bank accounts of over 2,000 users of a money management app, as well as self-reported financial well-being. We also find experimental evidence by manipulating SIW beliefs and observing causal effects on spending intentions. These results show how underlying beliefs about the link between spending and wealth play a role in consumption decisions, and point to beliefs about the meaning of spending as a fruitful direction for further research.

Keywords: consumer finance, financial beliefs, financial vulnerability, financial fragility, conspicuous consumption 
Consumers regularly spend beyond their means. American consumers have been described as being on "an extended shopping spree: the ratio of personal outlays to disposable income rose from below 90 percent in the early 1980s to nearly 100 percent in 2007" (Cynamon and Fazzari 2008, 1). Since the early 2000s, aggregate household debt in the U.S. has been higher than disposable personal income (Dynan, Mian, and Pence 2012). These problems are not unique to the United States; like Americans, between a fifth and a half of respondents in seven European countries reported being unable to come up with the equivalent of $\$ 2000$ for an emergency (Lusardi, Schneider, and Tufano 2011). While some of these consumers have very low incomes, others are financially vulnerable because they spend beyond their means.

Spending is influenced by many factors. One that has so far received little attention is the meaning that people give to the act of spending. Our research examines this meaning, focusing specifically on beliefs about the extent to which higher spending implies that the spender has more wealth (beliefs that Spending Implies Wealth, or "SIW beliefs"). We find that people differ; about a third of our respondents agree that higher spending implies greater wealth, while two-thirds are inclined to disagree. Variation in these beliefs about whether spending implies wealth are not interchangeable with beliefs about other meanings of spending (like whether it implies self-control or saving). We further find that SIW beliefs are not redundant with other constructs that influence spending, like materialism, financial literacy, or self-control. Importantly, we demonstrate downstream consequences: consumers with stronger SIW beliefs spend more lavishly (controlling for their income) and are more financially vulnerable. Finally, we show that interventions which change SIW beliefs impact spending intentions. Our work demonstrates that the largely unexplored area of beliefs about the meaning of spending can 
provide additional explanatory power in understanding who spends beyond their means, and why.

\section{WHAT INFLUENCES SPENDING?}

Research in consumer behavior and marketing has speculated about many causes of higher spending. Some research describes the relation of resources to spending: As income increases, so does spending (Carroll 1997; Friedman 1957), albeit at different rates on different types of goods (Currid-Halkett 2017). Other research describes which types of people spend more, and how spending is related to personality traits (Fenton-O'Creevy and Furnham 2019; Weston et al. 2019), financial literacy (Fernandes, Lynch Jr, and Netemeyer 2014), sensation seeking (Wong and Carducci 1991), and materialism (Watson 2003). Still other work identifies situations that lead to higher spending, such as arguing that men spend more in times when there are more men relative to women (Griskevicius et al. 2012). Some explanations for high spending are supported by both individual differences and situational influences. One example is the argument that high spending represents a failure to engage self-control, which has been used to explain over-spending in general (Laibson 1997; O’Donoghue and Rabin 1999; Thaler and Shefrin 1981), and also to predict the situations in which people, with self-control resources depleted, are likely to spend more and save less (Baumeister 2002; Vohs and Faber 2003).

One theme that is relatively unexplored in these various approaches is the question of what meaning the act of spending has for consumers. Money itself means different things to different people (e.g., security versus freedom, Furnham, Wilson, and Telford 2012), so the same may be true for the act of spending. As actions can acquire meanings that are separate from the 
outcomes those actions produce (Dayan and Berridge 2014), the act of spending is likely to have meanings that go beyond acquisition. And, a better understanding of the meaning of spending may provide further insight into high spending and financial vulnerability.

\section{THE MEANING OF SPENDING}

One way to uncover what spending means is to ask what people think about others who spend. For instance, self-described "spenders" were seen as lower in self-control, and hence as less attractive romantic partners - although more exciting —-than self-described "savers" (Olson and Rick 2017). Thus, for many people spending might mean excitement, and saving might mean self-control. Similarly, asked to explain why some people in the United States are rich and others poor, some adolescents made statements like: "[The rich] have a lot of money" or "They might be poor because they waste their money on junk" (Flanagan et al. 2014). Such work suggests that spending can be interpreted in multiple ways: it might imply wealth, and it might also imply that one is - or is likely to become - poor because of wasting money.

As is clear from the examples above, there are many different meanings that people may assign to spending. We focus on the belief that spending implies wealth, because this represents a core and fundamental understanding that is likely to impact financial vulnerability. Some people, or people in some situations, may believe that higher spending implies greater wealth, since spending demonstrates the ability to spend. Others may believe that spending is uninformative about wealth; that spending does not imply higher or lower wealth. Still others might believe that higher spending implies lower wealth, since many forms of spending deplete the spender's assets. We conceptualize these beliefs as falling along a spectrum, ranging from 
low to high: that is, from the belief that there is a negative correlation between spending and wealth, to no correlation, to a strong positive correlation. We refer to this as a spectrum of spending implies wealth (SIW) beliefs.

Beliefs about whether spending implies wealth can be seen as a type of lay theory, or a belief about how aspects of the world work. Unlike attitudes or values, lay theories need not be evaluative - they do not necessarily indicate a behavior like spending is good or bad - they can be simply descriptive, telling "how things work" in ways that allow observers to make sense of ambiguous behavior and outcomes (Hong, Levy, and Chiu 2001; Plaks, Levy, and Dweck 2009). In this way, SIW beliefs, which capture the relationship between two things (spending and wealth), are different from most constructs previously studied in financial decision making, which are about one thing (income, financial knowledge, self-control, etc.).

Because SIW beliefs represent a fundamental inference people draw from spending, they may influence a person's own financial behavior and outcomes. We expected that within their own resource constraints, many people would spend in the way that they believe the rich spend. Many people aspire to be rich (Nickerson et al. 2003; Richins and Dawson 1992; Schwartz 1992); indeed, in English the word "rich" is inherently positive (synonyms include plentiful, abundant, well-off) and its opposite "poor" is inherently negative (synonyms include bad, deficient, pitiful). People believe the wealthier are more competent (Durante, Tablante, and Fiske 2017), happier, more satisfied with their lives, and healthier than the poor (Varnum 2013), although they see the poor as warmer (Durante et al. 2017). Adults have an implicit preference for rich over poor (Horwitz and Dovidio 2017) and negative attitudes toward the poor compared to the middle-class (Cozzarelli, Wilkinson, and Tagler 2001). Because most people find being rich more appealing than being poor, they are likely to act the way that they believe the rich act, 
to the extent that their own resources allow. Accordingly, we predicted that people with strong SIW beliefs (i.e., those who believe that the wealthy spend a lot) would, themselves, spend more lavishly.

We are not arguing that everyone who endorses a strong SIW belief will spend "beyond their means;" rather, we expect a strong SIW belief to lead people to spend more-more lavishly - than they otherwise would. Downstream, those who spend more lavishly (holding their income constant) will have less set aside in savings, may thus be more likely to struggle to meet their financial commitments, and may become financially vulnerable in terms of inability to fund emergency expenses. Because of the lavish spending habits that we expected to observe, we also predicted that people with stronger SIW beliefs would be more financially vulnerable, reporting lower levels of financial well-being and holding less in savings, compared to those who are demographically similar but have weaker SIW beliefs.

\section{THE PRESENT RESEARCH}

We investigated these hypotheses across six studies. First, we asked whether SIW beliefs predicted variation in actual financial transactions (study 1). We then manipulated SIW beliefs to show a causal effect on financial behaviors (study 2). Together, these two studies show that SIW beliefs have meaningful consequences. We then developed a scale to better measure individual differences in SIW beliefs (studies 3-5). While developing the scale, we examined whether SIW beliefs covaried with other beliefs about the meaning of spending, such as the extent to which it is wasteful, as well as beliefs about the meaning of not spending, such as whether it implies a 
preference for saving. A final study (study 6) used the scale and an intervention together to predict a meaningful spending outcome.

This work contributes to several bodies of research. First, it adds to the literature on status signaling and status inferences. Until recently, much more was known about signal sending - when and how conspicuous consumption is used to signal wealth and status (e.g., Han, Nunes, and Drèze 2010; Veblen 1899) — than signal receipt. One paper that did examine signal receipt found that consumers perceive sellers who consume conspicuously to be more competent, probably because these sellers seem wealthier (Scott, Mende, and Bolton 2013). We build on that work by directly measuring perceived wealth as a function of spending, showing that only some people are inclined to see higher spending as indicative of wealth, and further finding that these inferences predict financial vulnerability. By doing so, our research also contributes to research on consumer financial well-being (Greenberg and Hershfield 2019; Lynch Jr 2011; Netemeyer et al. 2018). As other recent work has begun to do (e.g., Chowdhry and Dholakia 2020) we show that financial well-being is shaped by psychological beliefs and not merely knowledge. This idea, and our findings, contributes to debates on policy measures that may improve consumer well-being, as we discuss in more detail at the end of the paper.

\section{STUDY 1: SIW BELIEFS AND OBJECTIVE FINANCIAL MEASURES}

We assessed the predictive link between SIW beliefs and outcomes in a field setting with high ecological validity, using over 2 million transaction records from the bank accounts of over 2,000 participants. This dataset was collected in collaboration with a UK-based money management app. The service provides users with an online financial dashboard by aggregating 
all debit (outgoing) and credit (incoming) transactions across a customer's bank accounts (e.g., checking accounts and credit cards). Consumers may—but are unlikely to- have other accounts they do not aggregate through this application, because the software's primary use is to track finances across all accounts that one uses to spend money. Thus, we believe the data capture all spending for most participants, apart from any cash transactions.

We measured users' SIW beliefs in a survey and paired these responses with their account data. To test whether people with stronger SIW beliefs spent less frugally and displayed signs of greater financial vulnerability, we constructed measures of lavish spending (i.e., proportion of spending that was in relatively extravagant categories) and financial vulnerability (i.e., lower savings and investments) from the transaction records.

Method

Participants. In June 2017, app customers received an emailed request to take part in a research study, for the chance to win a tablet computer. In total, 2,232 people completed the relevant survey items and consented to having their responses matched with their personal transaction data. The available number of transaction data-linked survey responses determined the sample size. The dataset contains over 2 million individual transaction records in total, over a 12-month study period. All customer data were anonymized before being analyzed (IRB: 13463/001).

Demographic information on users was limited. Age was collected from the date of birth provided when registering with the service $(M=38$ years, $S D=14.50$, Range $=18-87)$. The service does not collect data on gender; instead, gender was derived by running the first names of 
account users through a names database, which identified gender in just over half of the cases $($ Male $=42.2 \%$, Female $=12.9 \%$, Not known $=44.9 \%)$. Annual income was a self-reported measure taken when users signed up to the service, with nine categories ranging from less than $£ 10 \mathrm{k}$ (approximately $\$ 13,000$ ) to greater than $£ 80 \mathrm{k}$ (approximately $\$ 105,000)$ in $£ 10 \mathrm{k}$ increments. The modal response was $220-30 \mathrm{k}$ (35.3\%), which corresponds with the median pretax income in the UK of $£ 26,300$ for the $2015 / 16$ financial year (Office for National Statistics 2017). A small portion of participants did not self-report their income $(206,9.2 \%$ of total).

Procedure and measures. Constraints in the field setting meant we measured SIW beliefs with a single item: "I think people who spend more are wealthier than people who spend less" (1 $=$ strongly disagree, $7=$ strongly agree $)$. Responses ranged from 1 to $7(M=3.06, S D=1.46)$.

All purchases and withdrawals made by participants across their registered bank accounts were recorded for the year preceding the survey date. Individual transactions were automatically labelled with one of 277 spending categories (e.g., "Petrol," "Golf," "Investments"); users could also manually update the labelling of a transaction. The amount spent (in British pounds) in each category was aggregated over the 12 months of available data for each participant. The extent to which spending is lavish as opposed to frugal is primarily determined by the amount spent rather than where it is spent - for instance, one can be lavish or frugal at the grocery store. However, some categories more naturally lend themselves to lavish spending, because the prices of goods tend to be high.

To identify these categories and construct measures of lavish spending from the transaction data we had for each participant, we recruited a new set of British adults and had them rate each category, using a procedure preregistered at https://aspredicted.org/yz9xg.pdf. After removing four raters who failed an attention check, the ratings were based on 84 people 
( $74 \%$ female, $26 \%$ male; $M_{\text {age }}=39.3$ years, $S D=12.5$ ). Each rater was presented with each of the 277 bank-reported spending categories, in random order, and asked, "When a person spends money on this category, does it suggest they are more frugal/thrifty or more lavish/extravagant?" $(1=$ very frugal, $7=$ very lavish $)$.

Our primary indicator of lavish spending was the proportion of overall spending from a person's account that was in categories categorized as lavish. As preregistered, categories with average ratings higher than $1 \mathrm{SD}$ above the mean rated lavishness $(M=4.94)$ were considered lavish. These categories included "Designer Clothes" $(M=6.27)$, "Jewelry" $(M=5.82)$, and "Flights" $(M=5.39)$. See Web Appendix (table W2) for the categories and ratings. We aggregated spending across the lavish categories to create a total amount of spending on lavish goods $(M=£ 3,508.79, S D=4761.77)$. We then divided this number by the individual's total spending recorded by the app during the year, to create a proportion of their spending that was lavish, which we used as our objective indicator of lavish spending. With this measure, people spent around $8 \%$ of their total budget on lavish goods $(M=.078, S D=.08$, Median $=.055$, Range $=0-0.977$ ). The Web Appendix (section B) describes an alternative approach to calculating lavish spending, based on weighting each category by its rating, which produced converging results.

In addition to lavish spending, we were interested in financial vulnerability. Because these data reflect transactions rather than assets, as an objective indicator of financial vulnerability we summed the amount the user saved or invested during the year preceding the survey by aggregating all categories that included the words savings or investments; for example, "General Savings," "Investment Other," and "Pension or Investments" $(M=£ 7,415.64, S D=$ $£ 30,630.16$, Median $=£ 2.78$, Range $=£ 0-645,974 ; 49.7 \%$ of respondents had zero savings or 
investments on this measure). Scores were log transformed, after adding 1 to each response, prior to analysis. Higher values here indicated the user was less financially vulnerable (because they had more funds available in case of emergency).

Users may have pre-existing savings and investments which they did not add to during the year, and therefore we also included self-reported total savings and investments as an additional measure of financial vulnerability. These were categorical measures, asked separately for both savings and investments, with a 9-point response scale $(1=£ 0,2=£ 1-100,3=£ 100$ $500,4=£ 500-£ 1000,5=£ 1000-£ 5000,6=£ 5000-£ 10,000,7=£ 10,000-£ 50,000,8=£ 50,000-$ $\left.£ 100,000,9=£ 100,000_{+}\right)$. We added together the questions about savings and about investments, providing an ordinal score ranging between 2 and $18(M=8.79, S D=4.57)$. This self-reported measure of savings and investments was correlated with the objective measure calculated from the account data $r(2205)=.28, p<.001$.

Finally, as a second complement to the objective indicator of financial vulnerability, we administered a five-item financial well-being scale designed by the US Consumer Financial Protection Bureau (Consumer Financial Protection Bureau 2017; Netemeyer et al. 2018). Sample items include "My finances control my life" and "Because of my money situation, I feel like I will never have the things I want in life." We averaged scale responses $(1=$ strongly disagree, 7 = strongly agree ) and coded the scale so that higher numbers represent greater financial wellbeing $(M=4.37, S D=1.22, \alpha=.79)$.

Results and Discussion

Bivariate correlations between the study variables are in the Web Appendix (table W1). 
Lavish spending. We first asked whether respondents with stronger SIW beliefs spent their money more lavishly. We employed a fractional logit model because our preregistered measure of lavish spending was a proportion of total spending (bound between 0 and 1), and we included age, gender, and self-reported income as control variables. All predictors were entered simultaneously, and all regression coefficients reported here and in the later studies are unstandardized. As summarized in table 1, people with stronger SIW beliefs spent money on more lavish goods and services $\left(b=.044, z(2020)=2.45, p=.014, \mathrm{CI}_{95} \%=.01, .08\right)$. One might wonder whether it is appropriate to include 'flights' in the lavish spending category, because flights could also represent a business expense. After removing flights we find no change in our reported result $\left(\mathrm{b}=.047, z(2020)=2.67, p=.008, \mathrm{CI}_{95 \%}=.01, .08\right)$.

To give a feeling for the size of the effect, extrapolating from the model in table 1 , respondents high in SIW beliefs (1 SD above the mean) are predicted to spend nearly $13 \%$ more as a proportion on lavish goods than those with low SIW beliefs (1 SD below). When estimating spending as a raw amount, this equates to spending $£ 296(\sim 400)$ more each year on lavish goods and services.

Insert Table 1 about here

Lavish spending is typically also more conspicuous. We expected that SIW beliefs predict lavish spending, but not solely spending on conspicuous goods. Even if others are unable to observe spending, acting in a way that is consistent with how one believes the successful act is likely to feel more psychologically satisfying (Turner 1991). In research studies, the average participant believes the wealthier are more competent (Durante et al. 2017) and more satisfied 
with their lives (Varnum 2013). This perceived link between wealth and success may mean that people, in general, are inclined to emulate the way they believe the wealthy act. To give an example, if you believe that wealthy and successful people do not bring lunch from home, eating at your desk out of a Tupperware box may feel like something to avoid even if your office door is shut and your consumption would be inconspicuous. We collected additional ratings and conducted additional analyses, reported in the Web Appendix (section C), investigating the type of lavish spending (i.e., conspicuous or inconspicuous), and finding that SIW beliefs predict lavish spending not merely because of a confound between lavish and conspicuous spending.

Financial vulnerability. We next asked whether respondents with stronger SIW beliefs displayed greater financial vulnerability. As summarized in table 2, participants with a stronger SIW belief saved and invested less, on a trend level, as measured by their account data $(b=-.11$, $\left.t(2020)=-1.77, p=.077, \mathrm{CI}_{95 \%}=-0.23,0.01\right)$. Using the self-reported total savings and investments yielded similar results $\left(\mathrm{b}=-.15, t(2020)=-2.26, p=.024, \mathrm{CI}_{95} \%=-0.27,-0.02\right)$. Converting the self-reported categories into monetary amounts, a person with strong (+1SD) SIW beliefs would be expected to have savings $£ 1517.85$ (nearly \$2000) lower than someone with weak (-1SD) SIW beliefs, suggesting individuals with stronger SIW beliefs were more financially vulnerable. Finally, using the measure of financial wellbeing from the CFPB as the dependent variable, we found a consistent result: Participants with stronger SIW beliefs reported lower financial well-being $\left(\mathrm{b}=-.14, t(2020)=7.81, p<.001, \mathrm{CI}_{95 \%}=-0.11,-0.17\right)$. We plot the estimated regression slope in figure 1 for financial wellbeing (model 4).

Insert Table 2 about here 
Insert Figure 1 about here

In sum, an analysis of banking transaction data suggests that subjective beliefs about how spending implies wealth help to predict objective spending and financial vulnerability.

Consumers who viewed higher spending as more indicative of wealth spent proportionately more of their money on lavish goods, and they also had less savings and investments, making them more financially vulnerable. However, this study cannot establish the causal direction of the relation between beliefs and outcomes. That is, although we hypothesized that beliefs about the meaning of spending shape spending decisions and financial outcomes, it is possible that people who spend lavishly, or who find themselves financially vulnerable, come to believe that the wealthy spend a lot. To guide our further studies, it was important to know whether SIW beliefs do in fact have a causal effect on spending decisions. If they do, they may be a useful target for interventions; if not, then interventions targeting beliefs about spending and wealth to change financial vulnerability would be misguided. Accordingly, we next collected causal evidence by manipulating SIW beliefs and observing effects on the lavish spending that contributes to financial vulnerability.

\section{STUDY 2: MANIPULATING SIW BELIEFS}

Asking whether SIW beliefs have a causal influence on financial behavior requires manipulating these beliefs. Fortunately, such beliefs, which we conceptualize as a type of lay theory, are not necessarily stable over time (Poon and Koehler 2008). The malleability of lay 
theories underpins interventions that try to change outcomes such as academic achievement via changes to beliefs about the nature of intelligence (Yeager et al. 2016). Lay theories are most often experimentally manipulated by presenting people with persuasive information, frequently in the form of an article that makes a case consistent with one or another lay theory (Wilson and English 2017). We followed this approach, giving participants persuasive information about how spending and wealth are related that was consistent with either a weak or strong SIW belief. We predicted that this manipulation would affect their intention to spend frugally versus lavishly.

Method

Participants and design. The design and analyses were preregistered at https://aspredicted.org/wy35e.pdf. We used Prolific Academic (Prolific.ac) to recruit 1,600 UK citizens for $£ 1$ each. There were 1,626 complete responses; per the preregistration we excluded 31 who failed an attention check, leaving 1,595 respondents (67\% female, $32 \%$ male, $<1 \%$ other) ages 18-86 $(M=36$ years, $S D=12.55)$ with modal net annual household income of $£ 18.5 \mathrm{k}-£ 37 \mathrm{k}$. Participants were randomly assigned to a weak or strong SIW belief condition.

Procedure and measures. After initial measures (see Web Appendix, section K), participants were presented with a scanned page of a newspaper article (masthead Phoenix Tribune, dated March 4, 2019) and were asked to read the first article on the page. They were told, "We are interested in whether the text in the scan is legible. At the bottom of the article you are asked three questions about it. Please do your best to answer those questions accurately." The article, approximately 500 words long, was either titled "Big spenders often less wealthy" (weak SIW condition) or "Big spenders often more wealthy" (strong SIW condition) with relevant 
anecdotes and information in each (see Web Appendix, section D). Three short questions afterward ensured participants had read the article. As a manipulation check, participants indicated agreement $(1=$ strongly disagree, $7=$ strongly agree $)$ with the statement used to measure SIW beliefs in study 1 and two similar statements. ${ }^{1}$

As a dependent measure, participants then completed the windfall task described by Kim and colleagues (2017), which involved dividing an unexpected $\$ 20,000$ between seven categories (buy things I want or need; give to charity or church organizations; give or lend to friends or relatives; travel; pay off debts; invest or put in savings; other). As preregistered, we summed amounts that participants indicated they would allocate to investments, savings and paying down debts (ranged from 0 to $\$ 20,000, M=\$ 11,668, S D=5189$ ) as a measure of the intention to spend frugally rather than lavishly.

As a second indicator, we measured relative preference between five pairs of items, where each pair contained one more expensive item and one less expensive item. The domains of the item pairs (an outfit, a trip, a meal, a piece of furniture, a show) drew on the categories that had been coded as "lavish" in study 1 (e.g., designer clothing, antiques). By including several different domains, we could explore whether a link between SIW beliefs and spending might vary across purchases that were more experiential (trip, show) versus material (outfit, piece of furniture). For example, one question read, "A performer that you and your friend really like is going on tour. You are deciding whether to buy tickets to the live show or to watch the livestream online from home, which is much less expensive. Which do you feel inclined to choose?" ( 1 = definitely the live show, 6 = equally likely to choose either option, $11=$ definitely

\footnotetext{
${ }^{1}$ Items 1,3 and 4 in table 3.
} 
watch at home). We coded the responses for the five items so that higher numbers represented more frugal spending tendencies (see Web Appendix, section D for full text of all items).

We assessed demand effects using the method of McFerran and Mukhopadhyay (2013). After responding to the dependent variables, participants were asked, "What do you think was the purpose of the study?" and typed an answer (minimum 20 characters) in a text box. Their answers were coded by a research assistant, and 76 participants (4.8\% of the valid sample) who guessed that the newspaper article was intended to affect their spending choices were excluded from further analysis.

Results and Discussion

Reading the newspaper articles produced the intended effect on SIW beliefs $\left(M_{\text {StrongSIW }}=\right.$ $3.85, S D=1.40$ vs. $\left.M_{\text {WeakSIW }}=2.81, S D=1.20, t(1559)=15.88, p<.001, d=.80\right)$. In line with our preregistered hypothesis, participants in the strong SIW condition intended to spend less of their windfall on the combined preregistered outcome of paying off debt, saving, and investing $\left(M_{\text {StrongSIW }}=\$ 11,225, S D=5249\right.$ vs. $\left.\widetilde{M}_{\text {WeakSIW }}=\$ 11,956, S D=5156\right), t(1517)=2.74, p=.006, d$ $=.14$. We next tested which of the spending categories were influenced by our manipulation. As seen in figure 2, participants with induced strong SIW beliefs reported that they would spend more to "buy things I want or need" and "travel," and less to "invest or put in savings." The amounts participants would spend to pay off debts did not significantly differ by condition, perhaps because most participants imagined paying off all of their debts with a large windfall.

To provide some perspective on the magnitude of the effect of the SIW manipulation, participants in the weak SIW condition intended to use $6.5 \%$ more of the windfall on debt 
reduction, savings, and investments. Given that household savings in the US and most European countries is below $10 \%$ of disposable income (OECD 2020), such differences would have a real impact on household wealth accumulation over time.

Insert Figure 2 about here

One might argue that buying needed items is not lavish. Wants and needs were presented as a single category for two reasons. First, this is consistent with the use of this measure by previous authors (Kim et al. 2017). Second and more importantly, many items are difficult to categorize as wants versus needs. Food is needed to maintain life and health, so people may see their grocery story spending as a "need" even though much of it is driven by preferences for specific tastes and brands and therefore not strictly necessary to maintain life. Similarly, a new Apple computer that enables a student to do their schoolwork may be justified as a "need" even though the purchase price also reflects "want" elements. Our point is not that people should not spend on "wanted" items. However, because nearly all items do not have a resale value equal to or higher than their purchase price, spending on wants or needs is unlikely to decrease financial vulnerability. Accordingly, we believed it was appropriate to use a single category for spending on wants and needs.

Finally, participants in the strong SIW condition also made less frugal spending choices across various domains. There was a significant difference between the conditions in three out of the five scenarios (designer outfit vs charity shop, $M_{\text {StrongSIW }}=7.89, S D=2.87$ vs. $M_{\text {WeaksIW }}=$ $8.26, S D=2.75), t(1517)=2.59, p=.010, d=.13$; flight vs bus ticket, $M_{\text {StrongSIW }}=7.34, S D=$ 3.38 vs. $\left.M_{\text {WeakSIW }}=7.68, S D=3.32\right), t(1517)=1.98, p=.048, d=.10$; takeout vs restaurant, 
$M_{\text {StrongSIW }}=4.90, S D=3.03$ vs. $\left.M_{\text {WeakSIW }}=5.21, S D=3.12\right), t(1517)=1.95, p=.051, d=.10$;

antique vs low quality furniture, $M_{\text {StrongSIW }}=7.27, S D=3.01$ vs. $M_{\text {WeakSIW }}=7.26, S D=3.01$ ), $t(1517)=0.03, p=.98, d=.003$; live show vs watching at home, $M_{\text {StrongSIW }}=4.89, S D=3.51$ vs. $\left.\left.M_{\text {WeakSIW }}=5.13, S D=3.59\right), t(1517)=1.29, p=.20, d=.07\right)$. Thus, effects emerged on items that pertained to both experiences and material goods, although participants on average would be less frugal when considering going to a restaurant or live show. Taking an average of the five items, participants in the strong SIW condition made less frugal spending choices $\left(M_{\text {StrongSIW }}=\right.$ $6.46, S D=1.67$ vs. $\left.\left.M_{\text {WeakSIW }}=6.71, S D=1.63\right), t(1517)=2.96, p=.003, d=.15\right){ }^{\circ}$

In sum, study 2 showed that manipulating beliefs about the extent to which spending implies wealth has a causal effect on consumer preferences for lavish versus frugal spending. ${ }^{2}$ With this evidence that SIW beliefs can have a causal impact on financial outcomes, we next undertook to develop a scale to better measure and understand these beliefs.

\section{STUDY 3: ITEM PURIFICATION AND SCALE CONSTRUCTION}

To further assess the downstream consequences of SIW beliefs for spending and financial vulnerability, we wanted to develop a reliable instrument to measure these beliefs. In study 3 , we drew on our theoretical definition to generate a large set of items and then reduced these to a parsimonious internally consistent scale of SIW beliefs. While developing the scale, we explored whether other meanings of spending systematically covary with SIW beliefs. That is, do people who believe that spending implies wealth also believe that spending does (or does not) imply wastefulness, or self-control, or a preference for saving? By including items about alternative

\footnotetext{
${ }^{2}$ See Web Appendix, section E, for a replication of this finding. See Web Appendix, section F for a study which asks whether increased financial hardship may also change SIW beliefs.
} 
meanings of spending, we could ascertain empirically whether these other meanings accompany beliefs about the link between spending and wealth.

The items we used referred to spending in vague terms (e.g. "spend a lot") that are open to interpretation, because we suspected that ambiguity would be important for scale items to capture the beliefs we were interested in. Probably few people would disagree that "People who spend hundreds of thousands of dollars annually on discretionary purchases are wealthy," so an item like this would not be a useful measure of variation. (Also, it would have to be revised, based on researcher judgment, when studying participants across places and over time, and our aim was to develop items that can be re-used by others with minimal revision.) "Wealth" is also vague - the dollar amount where someone is considered wealthy increases with respondents' own income. A statement where both pieces ("spending a lot" and "being wealthy") can be idiosyncratically interpreted is similarly useful for respondents with low and high incomes the way that a more specific statement ("Someone who spends $\$ 1,000$ a year on travel probably has a net worth more than $\$ 200,000 ")$ would not be. More generally, while spending is often visible, income rarely is. Inferences about wealth based on the judgement that someone "spends a lot" (idiosyncratically defined) seem to be much more common than inferences based on judgments about the proportion of income someone spends or the absolute dollar amount they spend. We were ultimately interested in these sorts of everyday inferences, and we believed that ambiguously worded statements would best capture them.

\section{Method}


Item generation. Using the reasoning outlined above as well as the qualitative responses collected in a supplementary study (see Web Appendix, section G), we generated 35 items. For example, some respondents' reasoning in the supplementary study was based on reflection about people they had encountered (see table W5 for an example). Based on those responses, our pool of items included two statements about people a respondent had encountered.

We initially assessed the clarity of the items in the pool by having five research assistants (undergraduate and graduate students) identify items that were unclear or which poorly mapped onto our construct. After further considering criteria such as face validity and semantic redundancy, we chose 29 items to administer to participants (see Web appendix, section H for full list). Roughly $2 / 3$ of the items stemmed directly from the concept of spending implying wealth, and the remaining $1 / 3$ were about alternative but potentially related meanings of spending such as wastefulness (e.g., "People who spend a lot of money are wasteful"), selfcontrol (e.g., "People who spend a lot of money don't have much self-control,"), or debt (e.g., "Spending a lot of money usually leads to going into debt").

Participants. We recruited participants from a nationally representative sample, so that the potential scale items could be tested on a sample reflecting the full range of the target population (Clark and Watson 1995). We therefore paid the panel provider Prolific to recruit a sample of 1000 respondents stratified to match the United States population distribution of age, sex, and ethnicity $(\mathrm{N}=1004$ completed responses, $51.3 \%$ female, $48.4 \%$ male, $.3 \%$ other, ages $18-84, M=43.9$ years, $S D=15.7$, modal household income $=\$ 90 \mathrm{k}$ to $\$ 149 \mathrm{k})$ to answer the scale items. By recruiting a large sample, our goal was to minimize measurement error and provide results that are more generalizable to the true population structure (MacCallum et al. 1999).

Participants were presented with the 29 items in randomized order and responded to each 
on a 7 -point scale $(1=$ strongly disagree, $7=$ strongly agree $)$. Included in the item list were two instructed-response attention checks (Kung, Kwok, and Brown 2018; Meade and Craig 2012; Thomas and Clifford 2017): "Please select 'agree' to show that you read questions carefully." A total of 963 (95.9\%) participants passed the attention checks; the remaining 41 were removed from further analyses.

Results and Discussion

Our goal was to reduce the number of items to ensure that only parsimonious and internally consistent items were included in the scale (Thurstone 1947). We balanced the benefits of improved psychometric properties with efficiency, as a measure with too many items would be time-consuming and redundant, a measure with unrelated items would be difficult to interpret (e.g., if the scale captured many meanings of spending that did not consistently covary), and a measure with too few items would not provide sufficient reliability. We summarize the results here and provide additional details on the analyses in the Web Appendix (section $\mathrm{H}$ ).

The first step was to remove items which had low item-rest correlations (Raykov and Marcoulides 2011), which represent the correlation between the item and the sum score of the rest of the items excluding itself. We deleted items in stages, removing those with item-rest values below .3, before re-calculating the item-rest correlations, repeating this until all item-rest values were above .3 . This process removed 15 items leaving 14 items remaining. The second step was to run a principal components analysis (PCA) to assess the factor structure and eliminate ill-fitting items. We again completed this step repeatedly after removing the item with the lowest loading onto the most common factor. For example, the item with the lowest factor 
loading (.104) was "People who spend a lot of money probably don't have much in savings." We repeated the process until all component loadings were higher than .3, leaving 7 items remaining.

Re-running the PCA on the remaining 7 items revealed one component with an eigenvalue greater than 1 (eigenvalue: 3.85). This component accounted for $55.1 \%$ of total variance, suggesting a single factor model is adequate to represent the majority of variance in SIW beliefs. The internal consistency of the 7-item scale was high, with a Cronbach's $\alpha$ of .86, and the level of internal consistency would not improve by removing any of the remaining items. The seven individual items for the scale are presented in table 3 . Note that the single item used in study 1 is included in the scale (Item 4, Item-rest $r=71$ ), suggesting that the item used in that study taps the same underlying construct as the full scale.

Using this procedure, none of the items designed to measure alternative meanings about spending were included in the final scale, indicating that none of these items tapped sufficiently into the primary underlying source of variance reflecting the belief that spending implies wealth. Thus, people who believe that spending implies wealth do not necessarily also believe that spending does (or does not) imply wastefulness, self-control, or a preference for saving. Similarly, people with strong or weak SIW beliefs have not necessarily consistently encountered frugal or lavish wealthy people. In sum, other meanings of spending may also vary in consequential ways, but they need to be investigated separately rather than as an aspect of beliefs about spending and wealth.

Insert Table 3 about here 
The range of scores on the scale is illustrated in the density plot in figure 3 , which visualizes the distribution of SIW beliefs. The distribution is characterized by a unimodal distribution (a single peak), and a slight positive skew, with its peak shifted toward the lower end of its range $(M=3.05, S D=1.10$, Median $=3.00$, Range $=1-6.86)$. A majority of people disagreed that spending implies wealth, but a substantial minority (34\% of respondents) were above the scale midpoint of 3.5 , indicating some agreement that spending implies wealth. The variance in responses suggests that people range from believing in a negative correlation (higher spending implies lower wealth), to an uninformative relation (higher spending tells little about wealth), to a positive correlation (higher spending implies higher wealth).

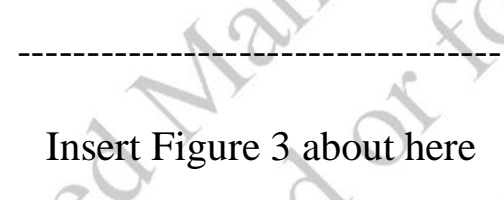

Given the diversity in the sample, we examined whether SIW scale scores differed across demographic groups. We ran an OLS linear regression with age, education $(1=$ no qualifications to $5=$ master's degree or higher $)$, income $(1=$ under $\$ 15 k$ to $10=$ over $\$ 200 k)$ and gender as simultaneous predictors of SIW beliefs. As older consumers have had more time to experience the relation of spending to wealth, it is possible they hold weaker SIW beliefs. However, we found no relationship between SIW scores and age $\left(b=.002, t(934)=.75, p=.45, \mathrm{CI}_{95 \%}=-.003\right.$, .01). Similarly, there was no association between education and SIW beliefs $(b=.0002, t(934)=$ $\left..00, p=.99, \mathrm{CI}_{95 \%}=-.08, .08\right)$. We did find that men held stronger SIW beliefs than women on average $\left(b=-.19, t(976)=-2.69, p=.007, \mathrm{CI}_{95 \%}=-.33,-.05\right)$, but the difference was small. We also observed a significant effect of income, with those with lower incomes more likely to 
endorse SIW beliefs $(b=-.078, t(934)=-5.13, p<.001, \mathrm{CI} 95 \%=-.11,-.048)$. In subsequent studies we control for income in analyses that predict financial outcomes from SIW beliefs.

Nine months after the initial study, we recruited 317 of the same study participants $\left(M_{\text {age }}\right.$ $=48.7,48.6 \%$ male) to retake the seven items in order to investigate the test-retest reliability. The items again had a high internal consistency (Cronbach's $\alpha$ of .92), and the test-retest reliability was $r=.68, p<.001$, which shows a moderate degree of stability. Moderate stability is consistent with the way we conceptualize SIW beliefs as a lay theory, which is relatively consistent but can also change over time and across contexts. Fluctuation over contexts is necessary to be able to manipulate lay theories, as we did in study 2 and do again in study 6 .

\section{STUDY 4: DISCRIMINANT AND NOMOLOGICAL VALIDITY}

We expected some overlap but believed that SIW beliefs could be empirically distinguished from seemingly similar constructs measured in previous research. We examined materialism, which comprises beliefs that possessions (usually acquired by spending money) determine success and happiness and are central to one's life (Richins 2004). SIW beliefs and materialism seem related but are conceptually distinct because SIW beliefs do not pertain to whether the wealthy spending a lot is good, important, or desirable. Instead, the belief that spending implies wealth simply describes whether the wealthy do spend a lot, which unlike materialism is a descriptive rather than prescriptive belief. Given this difference, we expected that SIW beliefs and materialism would be empirically distinguishable, which is an important preliminary step in assessing incremental validity (Wang and Eastwick 2020) — that is, before testing whether SIW beliefs help predict financial outcomes over and above materialism. At the 
same time, we also examined how SIW beliefs related to (low) self-control and to financial literacy, which are often studied as causes of financial vulnerability and lavish spending.

Our second goal with this study was to validate the scale in a new sample of participants. This is important because running exploratory and confirmatory analysis on the same set of participants can bias results (Browne and Cudeck 1992; Cabrera-Nguyen 2010). We recruited participants from the U.K. to complement the previous sample from the U.S.

Method

Participants. We used Prolific.ac to recruit 400 U.K. citizens for $£ .70$ each. There were 403 complete responses; we excluded 23 who failed an attention check, leaving 380 respondents (73\% female, $27 \%$ male, ages $18-75, M=36$ years, $S D=11.83$ ).

Measures. We administered the 7-item SIW belief scale. We also administered the short (9-item) Material Values Scale (Richins 2004), which includes subscales for success, happiness, and centrality; the Brief Self-Control Scale (Tangney, Baumeister, and Boone 2004), and a 12item test of financial literacy (Fernandes et al. 2014; we omitted one question that is specific to the US). All measures, including those not analyzed in the manuscript, are provided on the OSF site.

Results and Discussion

Scale validation in new sample. To further examine the psychometric properties of the SIW measure, we conducted a confirmatory factor analysis (CFA) using maximum likelihood. 
Standardized factor loadings ranged from .71 to .82 , and were all highly significant $(<.001)$. The 7 items comprising the SIW scale had an excellent model fit $(\mathrm{CFI}=.93 ; \mathrm{SRMR}=.05)$, indicating the items are reliable indicators of the SIW construct (Hair et al. 2006). Cronbach's $\alpha$ was high at .914 , and not improved by removing any single item. The first component from the PCA explained $66 \%$ of the shared variance, with an eigenvalue for the first component of 4.6, which dropped to .75 for the second one. These results in a new sample from a different country support the unidimensional structure and internal reliability of the SIW belief scale.

Discriminant validity. To verify that SIW beliefs could be distinguished from potentially related constructs, we first considered how correlated the measure was with these other scales. Importantly, none of the correlations were high enough to suggest SIW lay theories are interchangeable with the other constructs (table 4).

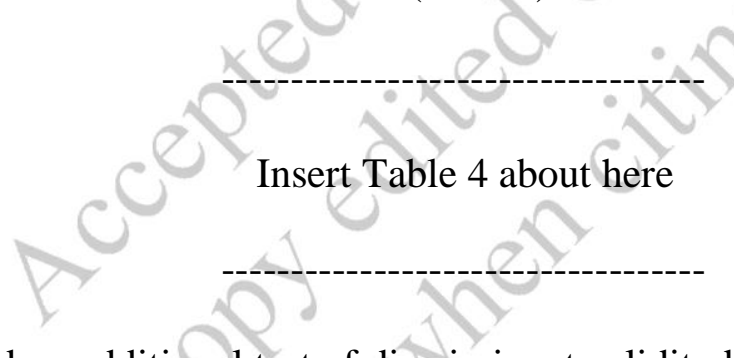

We conducted an additional test of discriminant validity by comparing the amount of the variance captured by the SIW construct to the variance shared with these other constructs. We were interested primarily in the relationship with the Material Values Scale (Richins 2004), as we considered this scale to have the greatest conceptual overlap with the SIW measure. After running confirmatory factor analyses between the spending-implies-wealth construct and both the combined Material Values Scale and each of its three subscales, we compared whether the average variance extracted (AVE) for each construct - which measures the level of variance captured by a construct versus the level due to measurement error-is greater than the squared correlation between the two constructs (Fornell and Larcker 1981). In no case was the squared 
correlation large enough to be a concern $\left(r^{2}=.01-.09\right)$ and the AVE from the latent variable for spending implies wealth was .61, above the generally accepted cut-off of .5. These two tests provide convergent evidence that SIW beliefs are empirically distinguishable from other related constructs. Given this supportive evidence, we next used the SIW belief scale to predict spending decisions.

\section{STUDY 5: SIW BELIEFS PREDICT SPENDING DECISIONS}

We used our validated scale to replicate the finding from study 1 that SIW beliefs predicted more lavish spending, this time using the full scale instead of a single item. We also wanted to ensure that the SIW belief scale has incremental validity - that it predicts spending over and above material values, since there is ample evidence that materialism also shapes spending decisions (Brown et al. 2016; Watson 2003).

Method

Participants. We used Prolific.ac to recruit 300 people in the US for $£ .70$ each. There were 303 complete responses; we excluded 24 who failed an attention check, leaving a sample of 279 participants ( $42 \%$ female, $56 \%$ male, $2 \%$ other) ages 18 to $76(M=35$ years, $S D=12.54)$ with modal net annual household income of $\$ 90 \mathrm{k}-\$ 149 \mathrm{k}$.

Procedure and measures. We administered the SIW beliefs scale $(\alpha=.91, M=2.92$, $S D=1.22$, Range $=1.00-6.14)$ and the Material Values Scale $(\alpha=.84, M=3.99, S D=1.09)$. As indicators of spending, after the other items, participants completed the windfall task (amount 
spent to pay off debts and invest/put in savings $M=\$ 11,626.68, S D=5,340.61$ ), as described in study 2. Additional measures and analyses are in Web Appendix, sections I and K.

Results and Discussion

We used linear regression analyses to predict both measures of spending from SIW beliefs, controlling for income (excluding 3.9\% of participants who preferred not to report their income) and materialism, with all predictors entered simultaneously. SIW beliefs predicted using less of the windfall to pay down debt and save or invest $(\mathrm{b}=-728.91, t(264)=-2.72, p=.007$, $\left.\mathrm{CI}_{95 \%}=-1255.78,-202.04\right)$. For example, a participant with low (1 SD below the mean) SIW beliefs is predicted to put away $\$ 12,524.87$, compared to one with high ( $1 \mathrm{SD}$ above the mean) SIW beliefs predicted to put away $\$ 10,728.49$, an increase of $17 \%$ more money allocated to debt repayment and savings/investments.

In these analyses, participants with higher incomes intended to spend more of their income to pay down debt and save or invest, on a trend level $(b=238.65, t(264)=1.91, p=.058$, $\left.\mathrm{CI}_{95 \%}=-7.81,485.11\right)$, while materialism did not predict windfall spending $(\mathrm{b}=199.47, t(264)=$ $\left.0.65, p=.52, \mathrm{CI}_{95 \%}=-404.44,803.38\right)$.

The amount allocated in the windfall task replicates the preregistered approach of study 2, which summed the amount used to pay off debt and save or invest as an indicator of frugal spending. As in study 2, we conducted follow-up analyses to probe the spending categories, and found that SIW beliefs significantly predicted spending in two of the categories. To visualize this, we present the proportion participants spent on each category across the range of SIW beliefs. We used a multivariate path analysis to predict the proportion allocated to each category 
by SIW beliefs, and plot these results in figure 4. This showed that while the proportion spent on most categories was consistent across the range of SIW beliefs (indicated by flat lines), investing and saving went down and spending on wants and needs went up. Someone with the lowest SIW beliefs (value $=1$ ) would be expected to save and invest around $46 \%$ of their windfall, while someone with the highest SIW beliefs (value $=7$ ) would only save and invest $24 \%$ of the windfall. In contrast, someone with the lowest SIW beliefs would be predicted to spend $13 \%$ of the windfall on wants and needs, and someone with the highest SIW beliefs would be predicted to spend $38 \%$.

\section{Insert Figure 4 about here}

These results converge with studies 1 and 2; again, beliefs about spending implying wealth predicted spending decisions. This time, the evidence came with our 7 -item scale rather than a single item (study 1) or a manipulation (study 2), and the predicted pattern of results was present after controlling for materialism. The final study looked to replicate the effect of SIW beliefs, looking at consequential spending rather than self-reported spending intentions.

\section{STUDY 6: SIW BELIEFS PREDICTING AND AFFECTING CONSEQUENTIAL SPENDING}

In a final study, we tested the relationship between SIW beliefs and a more consequential spending decision, where participants were asked to bid on a tablet computer they could receive as a prize. This study both measured SIW beliefs using the scale we developed (studies 3 and 4) 
and also included a manipulation of beliefs based on materials similar to those employed in study 2. Including both a measure of beliefs and a manipulation allows us to consider the strength of the effect of the brief intervention in comparison to the relationship we would expect based on people's pre-existing beliefs about whether spending implies wealth. The study also allowed us to test an alternative manipulation compared to the one used in study 2 (and replicated in a study described in Web Appendix, section E), with shorter, more engaging materials.

Method

Participants and design. We used Prolific.ac to recruit 600 UK participants for $£ 0.50$ each. There were 597 complete responses; we excluded 32 who failed an attention check, leaving $565(71 \%$ female, $29 \%$ male, $<1 \%$ other, ages $18-73, M=37.20$ years, $\mathrm{SD}=12.45)$ with modal net annual household income of $£ 50 \mathrm{k}$ to $£ 69 \mathrm{k}$. Participants answered the SIW scale questions and were then randomly assigned to receive information consistent with strong or weak SIW beliefs.

Procedure and measures. The study began by asking demographic questions, and then measuring SIW scale items mixed randomly with filler items to mask the goal of the study. We administered the SIW items before rather than after the manipulation, as we wanted to see if scale responses predicted our dependent variable, without responses to these items being influenced by the manipulation.

Next, we introduced a short manipulation similar to that described in study 2. Participants were told they would be reading news articles: "Now you will see excerpts from 3 different news articles. These articles have appeared on various online sites over the last 10 years." At this point, participants were randomly assigned to one of two conditions. In the strong 
SIW condition, participants saw headlines such as "How the Super Rich Spend their Money" with excerpts that described a link between extravagant spending and wealth. In the weak SIW condition, headlines included "Wealth is What You Save, Not What You Spend," with excerpts describing a negative link between spending and wealth. Participants viewed the articles and then wrote a few sentences summarizing what the articles were about. All headlines and excerpts had been published previously as real online articles (Web Appendix, section J).

We then administered two measures of lavish spending. Our main measure of interest was the amount that participants were willing to bid on a new tablet computer. Participants read:

Now, we are giving one participant a chance to buy a brand new iPad (32GB storage) at a substantial discount. This iPad sells for £349. The iPad will be sold to the participant who gives the highest bid. When all participants have completed the survey, we will identify the highest bidder and contact that person via Prolific messaging system. We will arrange for the high bidder to pay us their bid, and we will send them the new-in-box iPad. For example, if every other participant bids $£ 0$, and you bid $£ 1$, we will sell you the iPad for $£ 1$. If you bid $£ 199$ and every other participant bids $£ 198$ or less, we will sell you the iPad for $£ 199$. Please think about the highest amount you would be willing to pay for this new iPad and mark your bid below. Note that you are agreeing to pay that amount to the researchers if your bid is the highest submitted, in exchange for the iPad.

Bids for the iPad ranged from $£ 0$ to $£ 325$ ( $M=£ 39.76, S D=59.11)$. As a secondary measure, we asked participants to rate agreement with three statements adapted from a scale of frugality described by Lastovicka and colleagues (1999), adapted to reflect current frugal attitudes rather than existing tendencies to act in frugal ways. The statements were "If you can re-use an item you already have, there's no sense in buying something new;" "It is good to be careful about how 
you spend your money;" and "People should discipline themselves to get the most from their money" $(1=$ strongly disagree, $7=$ strongly agree $)$. These statements were presented in a list of six, which included two irrelevant fillers (e.g., "If someone asks you for advice, you owe them an honest opinion") and an attention-check probe, in order to camouflage the purpose. We calculated a mean of agreement with these statements as an indicator of frugal attitudes ( $\alpha=.68$, $M=6.13, S D=.81)$. Because our primary outcome was a consequential spending decision, we did not probe for demand, as we reasoned that demand effects would not be strong enough to affect participants' bids for the tablet computer when using their own money.

Results and Discussion

As the distribution of iPad bids was right-skewed, and represented a count bound between 1-348, we modelled the bids as a truncated Poisson model. We found that both measured SIW scale scores and the manipulation both predicted higher bids. As expected, SIW scale scores were positively correlated with higher iPad bids $(b=.06, \mathrm{z}(565)=11.12, p<.001$, $\left.\mathrm{CI}_{95 \%}=.05, .07\right)$. In monetary terms, this means that each additional point on the SIW scale is expected to increase the iPad bid by $£ 2.48$. Additionally, the average bids for the iPad made by those in the strong SIW condition were $11.34 \%$ higher compared to those in the low SIW condition $\left(M_{\text {WeakSIW }}=38.25\right.$ vs $\left.M_{\text {StrongSIW }}=42.58\right)$, and the difference between the two conditions was significant $\left(b=.11, \mathrm{z}(566)=7.97, p<.001, \mathrm{CI}_{95 \%}=.08, .13\right)$. The effect of the manipulation held when controlling for baseline SIW beliefs and demographics (age, gender and income) ( $b=$ $\left..12, \mathrm{z}(554)=8.81, p<.001, \mathrm{CI}_{95 \%}=.09, .15\right)$. Figure 5 shows predicted iPad bids across the SIW scale, with the parallel lines representing the two experimental conditions. 
Insert Figure 5 about here

Participant's bids on the tablet computer had a high variance relative to their mean. To account for this overdispersion and to provide an additional degree of robustness, we repeated the analyses using a negative binomial regression model. The regression model, which included the control variables, showed that the effects of the SIW measure and manipulation on bid amounts remained comparable in size, but had wider confidence intervals after accounting for the overdispersion (SIW scale scores, $b=.07, \mathrm{z}(554)=1.84, p=.065, \mathrm{CI}_{95 \%}=-.00, .15$; SIW condition, $\left.b=.16, \mathrm{z}(554)=1.81, p=.070, \mathrm{CI}_{95 \%}=-.01, .33\right)$.

We had also measured a secondary outcome, self-reported agreement with the three statements about frugal spending. As expected, people with stronger SIW beliefs reported less frugal attitudes $\left(b=-.06, t(565)=-2.06, p=.040, \mathrm{CI}_{95 \%}=-.12,-.002\right)$. On this measure, the effect of the experimental manipulation was not significant, although directionally participants in the strong SIW condition reported lower frugal attitudes $\left(M_{\text {WeaksIW }}=6.18\right.$ vs $M_{\text {StrongSIW }}=6.08$, $t(563)=1.45, p=.147, d=.12)$. Although this small effect may not be reliable, it suggests that participants in the strong SIW condition did not merely bid more because they believed they were competing with others who had just read information that would lead them to bid highly.

Results of this study provide additional evidence of the SIW scale's predictive validity, this time in terms of a consequential decision. Presenting evidence consistent with a strong or weak SIW belief — even more briefly than we had done in study 2 - also had an effect on this decision, suggesting that this type of information may be a fruitful basis for interventions that change spending. 


\section{GENERAL DISCUSSION}

Prior research has identified many dispositional and situational factors that influence spending, but little is known about the meaning people give to the act of spending. We investigated this meaning in terms of the extent to which higher spending implies greater wealth. We observed that people range from believing in a negative correlation (higher spending implies lower wealth), to an uninformative relation (higher spending tells little about wealth), to a positive correlation (higher spending implies higher wealth). These SIW beliefs predict spending and financial vulnerability, in ways that are not explained by differences in income.

These findings contribute to research in consumer behavior by identifying a previously unexplored construct that helps predict consequential financial outcomes. Research in psychology has shown that actions can acquire meanings that are separate from the outcomes those actions produce (Dayan and Berridge 2014), and separately, both research and lay writing has begun to explore the difference between income and wealth (Housel 2020; Moulton et al. n.d.). Our studies suggest that for many people, the act of spending has a meaning (higher wealth) that is separate from the outcome the act produces (which in many cases is depleting wealth and increasing financial vulnerability). Considering the meaning of actions gives a new way to interpret previous, potentially puzzling, findings. For example, people higher in materialism—who place more value on acquiring and possessing material objects—-made discretionary purchases more often than people with the same household income who were lower in materialism (Brown et al. 2016). However, high materialists experienced more negative affect after their purchases, even though they endorsed statements like "buying things gives me a lot of pleasure." The fact that people high in materialism make more discretionary purchases even 
though they seem to feel bad afterwards suggests that perhaps the act of acquisition is itself meaningful. Our studies showing that spending can imply wealth highlight one such meaning that spending may have for people high in materialism (keeping in mind that SIW beliefs and material values were only moderately correlated in study 4). More generally, there is a growing focus in marketing on consumer financial well-being (Greenberg and Hershfield 2019; Lynch Jr 2011; Netemeyer et al. 2018), and understanding what spending means to different groups of consumers provides a novel mechanism that can be targeted through interventions or training.

The relation of SIW beliefs to measures of spending and financial vulnerability was generally small, in line with most effects identified in psychological research (Schäfer and Schwarz 2019). Consumer behaviors are strongly shaped by situational goals and norms and other individual differences, and therefore, while the influence of SIW beliefs may be small when considering isolated tasks, the meaning of spending may contribute an important degree of explanatory variance when considered across a wider range of consumer contexts. In other domains (e.g., education), interventions that change lay theories such as those about the nature of intelligence have also produced small, but arguably useful, effects (Dweck 2018). Moreover, effects that are small in terms of explained variance can be large when considered in the original metrics (Matz, Gladstone, and Stillwell 2017). As examples from the present research, respondents low versus high in SIW beliefs had a difference in savings of over $£ 1500$ (roughly $\$ 1950$ at the time of the study) in study 1, and intended to transfer 6\% (study 2, manipulated beliefs) or $17 \%$ (study 5 , measured beliefs) more to savings. The effect size in study 2 when beliefs were manipulated $(d=0.14)$ means that roughly 18 people would need to be given the intervention in order to help move one person (with income that would permit saving) out of financial vulnerability (Magnusson 2020). Given the magnitude of the spending challenges 
facing the US, UK, and similar countries — where half or more of households may be unable to fund emergency expenses without seeking high-cost credit (Lusardi et al. 2011)—even small gains in understanding who spends beyond their means, and why, are extremely beneficial.

Potential Moderators of the Link between SIW Beliefs and Financial Outcomes

Stronger SIW beliefs predict that people spend more lavishly and are more financially vulnerable, compared to others with similar demographic characteristics and income but weaker SIW beliefs. There are likely factors that influence the strength of this relation. For instance, living in a community where it is acceptable and normative to spend highly may strengthen the relation of SIW beliefs to spending, whereas living in a community that frowns on spending, or where there are limited opportunities to spend, may dampen this relation. And, people who spend lavishly but have rising incomes or rising property values may not become financially vulnerable to the same extent as those who are less fortunate.

The relation of SIW beliefs to financial outcomes that we describe are predicated on the assumption that a person finds wealth at least modestly aspirational—we expect that people spend the way they believe the wealthy spend because of the general appeal of being rich rather than poor. Given this assumption, we speculated that the extent to which people value wealth and financial success may also moderate the effect of SIW lay beliefs on lavish spending. The spending behavior of people who care very strongly about wealth would be more affected by their SIW beliefs, and those who do not desire to be wealthier should not be affected by such beliefs. The Web Appendix (section K) describes tests of this moderator hypothesis in three studies, with mixed results. Two points are worth making. First, adults have an implicit 
preference for wealth over poverty (Horwitz and Dovidio 2017). Thus, even people who report on a scale that they do not value wealth may still be implicitly guided by their beliefs about how the rich spend, which may account for failure to find significant moderation in many analyses. Second, many societies are marked by negative attitudes toward the poor (Cozzarelli et al. 2001). Even people who do not value wealth may not want to be perceived - by themselves or othersto act as they believe poorer people act. On the operational level, it may also be useful in future research to examine admiration for or liking of the rich as a moderator rather than the ambition to be rich. Future research on moderators of the effects of SIW beliefs can build on these points to shed further light on how beliefs about the meaning of money relate to financial outcomes.

Implications for Policy

Policymakers are increasingly concerned with tackling financial vulnerability, including how people balance consumption and savings. Governments and charitable foundations already spend large sums encouraging citizens to save money through messaging and educational campaigns (Personal Finance Research Centre, University of Bristol and Ipsos MORI 2018), and our results can contribute to the design of interventions and messages aimed at changing attitudes. Our results show that spending does not imply wealth for everyone, and the materials we used to experimentally induce weak SIW beliefs (studies 2,6) lay a foundation for such messages. Further inspiration can be drawn from the growing popularity of the "Financial Independence, Retire Early" (FIRE) movement. Adherents to this community use frugality and extreme savings to retire decades earlier than the norm. In doing so, these individuals interpret low spending as building wealth (Kurutz 2017), with wealth representing freedom in how to 
spend time, rather than the accumulation of possessions or experiences. This interpretation allows for minimizing spending to be a status symbol in this group.

In fact, this approach may operate on a societal scale in parts of the world, like Japan, where the wealthy do not spend lavishly (Garon 2011). In the US and Europe, developing messaging to address underlying beliefs about the meaning of spending could be an important complement to existing financial-fitness training. Given that status hierarchies are one of the most universal constants across cultures (Anderson, Hildreth, and Howland 2015; Buss et al. 2020), changing ideas about how the wealthy act may be a more fruitful intervention than trying directly to decrease the desire for public status symbols.

However, in designing financial interventions, it is important to keep in mind that frugal spending is not necessarily better. Participants in study 6 who submitted very low bids for the tablet computer potentially lost a money-making opportunity; in general, consumers may regret restrained choices and may end up less happy as a result of very frugal spending (Kivetz and Keinan 2006). Moreover, lavish spending may, in fact, be functional for low-income or lowstatus consumers, because signaling wealth to others can improve one's status, with beneficial effects (Ashworth, Darke, and Schaller 2005; Lee and Shrum 2012; Nelissen and Meijers 2011). Despite these caveats, there is a need for interventions to help many consumers spend more frugally, particularly the many who have moderate or high incomes but also high debt and little emergency savings (Lusardi et al. 2011). Insecurity about being able to pay bills is a source of stress, poor mental health (Bridges and Disney 2010), and reduced life satisfaction (Ruberton, Gladstone, and Lyubomirsky 2016), so reducing spending to facilitate bill-payment and build emergency savings should improve mental health and life satisfaction for many consumers. Our 
work suggests that belief about spending and wealth can be changed momentarily. More work is needed to test whether these changes can be sustained, and to identify their longitudinal impact.

A further implication for policy is the potential for structural (rather than individual) changes to influence spending decisions. If one individual unilaterally reduces their spending while others spend as before, they are likely to feel deprived. One way to deal with this challenge is to reduce the incentives for everyone to spend more relative to others. This could be achieved through the tax system; a more progressive tax structure would reduce inequality and decrease the spending that is artificially boosted by others' high spending (Frank and Cook 2010). For instance, a family who decides not to buy an expensive house in a good school district may disadvantage their individual child's education. But if a progressive tax structure lowered housing budgets and hence lowered the price of expensive housing, half of all students would still attend better-than-median schools, with less money spent on housing overall. With this policy approach, less disparity in spending would be possible, and spending would, objectively, be less indicative of wealth. This should, in turn, reduce financial vulnerability by changing the degree to which spending is indicative of status and wealth.

Extensions and Future Research

We measured beliefs about the link between spending, in general, and wealth. Future research could build on this work by looking at which types of spending are more strongly linked to higher or lower wealth, and for which types of respondents. For example, previous research in psychology and marketing has explored the tendency to spend on visibly branded goods in order to convey status (Han et al. 2010). Visibly branded handbags may imply higher wealth to some 
participants and lower wealth to others. High spending on education might lead to different conclusions than high spending on branded goods, and again this could vary across the characteristics of the perceiver. These differences are worth exploring in future research.

Two of our studies (studies 2 and 6; see also Web Appendix, section E) suggested that SIW beliefs play a causal role in spending decisions. However, it is possible that this relation is bidirectional. Perhaps people who have spent lavishly or find themselves financially vulnerable rationalize their situations by believing this spending is what the wealthy do. Our Web Appendix (section F) describes a well-powered experiment that found only weak evidence for this reversecausal relationship, but we cannot rule out that there is a small causal effect of money management stress on SIW beliefs. We speculate that SIW beliefs may be shaped not so much by experiences of financial hardship in and of themselves, but more so by the way those experiences are interpreted. For instance, lay theories about intelligence appear to be based on the way that parents and important adults discuss relevant experiences. Research suggests that children who hear messages implying intelligence is a fixed quality (e.g., "you're a smart girl") come to endorse the lay theory that intelligence is fixed and cannot really be changed (Gunderson et al. 2013) A similar process may take place regarding money. In a supplementary study that collected open-ended responses (Web Appendix, section G) we found that people who believe spending implies wealth focus on the ability to spend; people who do not believe spending implies wealth focus on the effects of spending. Thus, children who hear messages implying spending is about ability (e.g., "we can't afford that, we're not rich") may come to believe that spending implies wealth. On the other hand, children who are helped to focus on the effects of spending (e.g., "if you buy that candy, you won't have any money left for the toy you wanted") might come to believe spending does not imply wealth. We expect that such messages, 
along with experiences like observing significant others' spending, lead people to develop the SIW beliefs that underpin a range of later consumption decisions. Testing this process directly with young children and parents is worthwhile. If ability messages do affect SIW beliefs, parents might consider trying to emphasize the effects of spending ("If we buy this, we won't be able to do that" or "If we don't buy this today, we'll have more choices next week") as they teach their children about money.

Conclusion

Although there are many explanations for over-spending, little has been known about consumers' underlying beliefs about how spending money is related to having money. The present studies show that people who believe the wealthy spend a lot also spend more of their own income, saving less and becoming more financially vulnerable. These findings contribute to a deeper understanding of how underlying beliefs about the meaning of spending relate to financial well-being. 


\section{DATA COLLECTION INFORMATION}

The second author collected and analyzed the data for study 1 (June 2017). The first author collected and analyzed the data for study 2 (via Prolific Academic in March 2019). The first and second authors jointly collected the data, and the second author analyzed the data, for study 3 (via Prolific Academic's panel service in August-September 2019) and study 6 (via Prolific Academic in February 2020). The first and second authors jointly collected and analyzed the data for study 4 (via Prolific Academic in October 2019) and study 5 (via Prolific Academic in November 2019). Data for all except study 1 is available at https://osf.io/ch5wm/. 


\section{REFERENCES}

Anderson, Cameron, John Angus D. Hildreth, and Laura Howland (2015), "Is the Desire for Status a Fundamental Human Motive? A Review of the Empirical Literature.," Psychological Bulletin, 141(3), 574.

Ashworth, Laurence, Peter R. Darke, and Mark Schaller (2005), "No One Wants to Look Cheap: Trade-Offs between Social Disincentives and the Economic and Psychological Incentives to Redeem Coupons," Journal of Consumer Psychology, 15(4), 295-306.

Baumeister, Roy F. (2002), "Yielding to Temptation: Self-Control Failure, Impulsive Purchasing, and Consumer Behavior," Journal of consumer Research, 28(4), 670-676.

Bridges, Sarah and Richard Disney (2010), "Debt and Depression," Journal of health economics, 29(3), 388-403.

Brown, Kirk Warren, Tim Kasser, Richard M. Ryan, and James Konow (2016), "Materialism, Spending, and Affect: An Event-Sampling Study of Marketplace Behavior and Its Affective Costs," Journal of Happiness Studies, 17(6), 2277-2292.

Browne, Michael W. and Robert Cudeck (1992), "Alternative Ways of Assessing Model Fit," Sociological methods \& research, 21(2), 230-258.

Buss, David M., Patrick K. Durkee, Todd K. Shackelford, Brian F. Bowdle, David P. Schmitt, Gary L. Brase, Jae C. Choe, and Irina Trofimova (2020), "Human Status Criteria: Sex Differences and Similarities across 14 Nations.," Journal of Personality and Social Psychology.

Cabrera-Nguyen, Peter (2010), “Author Guidelines for Reporting Scale Development and Validation Results in the Journal of the Society for Social Work and Research," Journal of the Society for Social Work and Research, 1(2), 99-103. 
Carroll, Christopher D. (1997), "Buffer-Stock Saving and the Life Cycle/Permanent Income Hypothesis," The Quarterly journal of economics, 112(1), 1-55.

Chowdhry, Nivriti and Utpal M. Dholakia (2020), “Know Thyself Financially: How Financial Self-Awareness Can Benefit Consumers and Financial Advisors," Financial Planning Review, 3(1), e1069.

Clark, Lee Anna and David Watson (1995), “Constructing Validity: Basic Issues in Objective Scale Development," Psychological Assessment, 7(3), 309-19.

Consumer Financial Protection Bureau (2017), “CFPB Financial Well-Being Scale: Scale Development Technical Report," Washington DC: CFPB.

Cozzarelli, Catherine, Anna V. Wilkinson, and Michael J. Tagler (2001), "Attitudes toward the Poor and Attributions for Poverty," Journal of social issues, 57(2), 207-227.

Currid-Halkett, Elizabeth (2017), The Sum of Small Things: A Theory of the Aspirational Class, Princeton University Press.

Cynamon, Barry Z. and Steven M. Fazzari (2008), "Household Debt in the Consumer Age: Source of Growth-Risk of Collapse," Capitalism and society, 3(2).

Dayan, Peter and Kent C. Berridge (2014), "Model-Based and Model-Free Pavlovian Reward Learning: Revaluation, Revision, and Revelation," Cognitive, Affective, \& Behavioral Neuroscience, 14(2), 473-492.

Durante, Federica, Courtney Bearns Tablante, and Susan T. Fiske (2017), "Poor but Warm, Rich but Cold (and Competent): Social Classes in the Stereotype Content Model," Journal of Social Issues, 73(1), 138-157.

Dweck, Carol (2018), “Growth Mindset Interventions Yield Impressive Results | SPSP," http://spsp.org/news-center/blog/growth-mindset-interventions-results. 
Dynan, Karen, Atif Mian, and Karen M. Pence (2012), "Is a Household Debt Overhang Holding Back Consumption?[With Comments and Discussion]," Brookings Papers on Economic Activity, 299-362.

Fenton-O’Creevy, Mark and Adrian Furnham (2019), “Money Attitudes, Personality and Chronic Impulse Buying," Applied Psychology.

Fernandes, Daniel, John G. Lynch Jr, and Richard G. Netemeyer (2014), “Financial Literacy, Financial Education, and Downstream Financial Behaviors," Management Science, 60(8), $1861-1883$.

Flanagan, Constance A., Taehan Kim, Alisa Pykett, Andrea Finlay, Erin E. Gallay, and Mark Pancer (2014), “Adolescents' Theories about Economic Inequality: Why Are Some People Poor While Others Are Rich?," Developmental Psychology, 50(11), 2512.

Fornell, Claes and David F. Larcker (1981), “Evaluating Structural Equation Models with Unobservable Variables and Measurement Error," Journal of marketing research, 18(1), 39-50.

Frank, Robert H. and Philip J. Cook (2010), The Winner-Take-All Society: Why the Few at the Top Get so Much More than the Rest of Us, Random House.

Friedman, Milton (1957), “The Permanent Income Hypothesis," in A Theory of the Consumption Function, Princeton University Press, 20-37.

Furnham, Adrian, Emma Wilson, and Kate Telford (2012), “The Meaning of Money: The Validation of a Short Money-Types Measure," Personality and Individual Differences, 52(6), 707-711.

Garon, Sheldon (2011), Beyond Our Means: Why America Spends While the World Saves, Princeton University Press. 
Greenberg, Adam Eric and Hal E. Hershfield (2019), "Financial Decision Making,” Consumer Psychology Review, 2(1), 17-29.

Griskevicius, Vladas, Joshua M. Tybur, Joshua M. Ackerman, Andrew W. Delton, Theresa E. Robertson, and Andrew E. White (2012), “The Financial Consequences of Too Many Men: Sex Ratio Effects on Saving, Borrowing, and Spending.," Journal of personality and social psychology, 102(1), 69.

Gunderson, Elizabeth A., Sarah J. Gripshover, Carissa Romero, Carol S. Dweck, Susan GoldinMeadow, and Susan C. Levine (2013), "Parent Praise to 1-to 3-Year-Olds Predicts Children's Motivational Frameworks 5 Years Later," Child development, 84(5), 15261541.

Hair, Joseph F., William C. Black, Barry J. Babin, Rolph E. Anderson, and Ronald L. Tatham (2006), Multivariate Data Analysis (Vol.6), Upper Saddle River, NJ: Pearson Prentice Hall.

Han, Young Jee, Joseph C. Nunes, and Xavier Drèze (2010), "Signaling Status with Luxury Goods: The Role of Brand Prominence," Journal of marketing, 74(4), 15-30.

Hong, Ying-yi, Sheri R. Levy, and Chi-yue Chiu (2001), “The Contribution of the Lay Theories Approach to the Study of Groups," Personality and Social Psychology Review, 5(2), 98106.

Horwitz, Suzanne R. and John F. Dovidio (2017), “The Rich—Love Them or Hate Them? Divergent Implicit and Explicit Attitudes toward the Wealthy," Group Processes \& Intergroup Relations, 20(1), 3-31.

Housel, Morgan (2020), The Psychology of Money: Timeless Lessons on Wealth, Greed, and Happiness, Harriman House Limited. 
Kim, Hyunji, Mitchell J. Callan, Ana I. Gheorghiu, and William J. Matthews (2017), “Social Comparison, Personal Relative Deprivation, and Materialism," British Journal of Social Psychology, 56(2), 373-392.

Kivetz, Ran and Anat Keinan (2006), "Repenting Hyperopia: An Analysis of Self-Control Regrets," Journal of Consumer Research, 33(2), 273-282.

Kung, Franki YH, Navio Kwok, and Douglas J. Brown (2018), “Are Attention Check Questions a Threat to Scale Validity?," Applied Psychology, 67(2), 264-283.

Kurutz, Steven (2017), "How to Retire in Your 30s With \$1 Million in the Bank - The New York Times,” The New York Times, https://www.nytimes.com/2018/09/01/style/fire-financialindependence-retire-early.html.

Laibson, David (1997), "Golden Eggs and Hyperbolic Discounting," The Quarterly Journal of Economics, 112(2), 443-478.

Lee, Jaehoon and L. J. Shrum (2012), “Conspicuous Consumption versus Charitable Behavior in Response to Social Exclusion: A Differential Needs Explanation," Journal of Consumer Research, 39(3), 530-544.

Lusardi, Annamaria, Daniel J. Schneider, and Peter Tufano (2011), Financially Fragile Households: Evidence and Implications, National Bureau of Economic Research, http://www.nber.org/papers/w17072.

Lynch Jr, John G. (2011), "Introduction to the Journal of Marketing Research Special Interdisciplinary Issue on Consumer Financial Decision Making," Journal of Marketing Research, 48(SPL), Siv-Sviii.

MacCallum, Robert C., Keith F. Widaman, Shaobo Zhang, and Sehee Hong (1999), "Sample Size in Factor Analysis," Psychological Methods, 4(1), 84-99. 
Magnusson, Kristoffer (2020), “Interpreting Cohen's d Effect Size: An Interactive Visualiation (Version 2.1.1) [Web App]," R Psychologist, https://rpsychologist.com/d3/cohend/.

Matz, Sandra C., Joe J. Gladstone, and David Stillwell (2017), “In a World of Big Data, Small Effects Can Still Matter: A Reply to Boyce, Daly, Hounkpatin, and Wood (2017)," Psychological science, 28(4), 547-550.

McFerran, Brent and Anirban Mukhopadhyay (2013), "Lay Theories of Obesity Predict Actual Body Mass," Psychological science, 24(8), 1428-1436.

Meade, Adam W. and S. Bartholomew Craig (2012), "Identifying Careless Responses in Survey Data.," Psychological methods, 17(3), 437.

Moulton, Vanessa, Alissa Goodman, Bilal Nasim, George B. Ploubidis, and Ludovica Gambaro “Parental Wealth and Children's Cognitive Ability, Mental, and Physical Health:

Evidence From the UK Millennium Cohort Study," Child Development.

Nelissen, Rob MA and Marijn HC Meijers (2011), "Social Benefits of Luxury Brands as Costly Signals of Wealth and Status," Evolution and Human Behavior, 32(5), 343-355.

Netemeyer, Richard G., Dee Warmath, Daniel Fernandes, and John G. Lynch Jr (2018), “How Am I Doing? Perceived Financial Well-Being, Its Potential Antecedents, and Its Relation to Overall Well-Being," Journal of Consumer Research, 45(1), 68-89.

Nickerson, Carol, Norbert Schwarz, Ed Diener, and Daniel Kahneman (2003), "Zeroing in on the Dark Side of the American Dream: A Closer Look at the Negative Consequences of the Goal for Financial Success," Psychological science, 14(6), 531-536.

O’Donoghue, Ted and Matthew Rabin (1999), "Doing It Now or Later," American Economic Review, 89(1), 103-124.

OECD (2020), “Household Savings (Indicator),” doi: 10.1787/cfc6f499-en. 
Office for National Statistics (2017), Household Disposable Income and Inequality in the UK:

Financial Year Ending 2016,

https://www.ons.gov.uk/peoplepopulationandcommunity/personalandhouseholdfinances/i ncomeandwealth/bulletins/householddisposableincomeandinequality/financialyearending 2016.

Olson, Jenny and Scott Rick (2017), “A Penny Saved Is a Partner Earned: The Romantic Appeal of Savers," Available at SSRN 2281344.

Personal Finance Research Centre, University of Bristol and Ipsos MORI (2018), What Works Fund: Evidence Analysis by Life Stage, https://www.fincap.org.uk/en/articles/whatworks-fund.

Plaks, Jason E., Sheri R. Levy, and Carol S. Dweck (2009), "Lay Theories of Personality: Cornerstones of Meaning in Social Cognition," Social and Personality Psychology Compass, 3(6), 1069-1081.

Poon, Connie SK and Derek J. Koehler (2008), "Person Theories: Their Temporal Stability and Relation to Intertrait Inferences," Personality and Social Psychology Bulletin, 34(7), 965-977.

Raykov, Tenko and George A. Marcoulides (2011), Introduction to Psychometric Theory, Routledge.

Richins, Marsha L. (2004), “The Material Values Scale: Measurement Properties and Development of a Short Form," Journal of consumer Research, 31(1), 209-219.

Richins, Marsha L. and Scott Dawson (1992), “A Consumer Values Orientation for Materialism and Its Measurement: Scale Development and Validation,” Journal of consumer research, 19(3), 303-316. 
Ruberton, Peter M., Joe Gladstone, and Sonja Lyubomirsky (2016), “How Your Bank Balance Buys Happiness: The Importance of 'Cash on Hand' to Life Satisfaction.,' Emotion, 16(5), 575.

Schäfer, Thomas and Marcus A. Schwarz (2019), “The Meaningfulness of Effect Sizes in Psychological Research: Differences Between Sub-Disciplines and the Impact of Potential Biases," Frontiers in Psychology, 10, https://www.frontiersin.org/articles/10.3389/fpsyg.2019.00813/full.

Schwartz, Shalom H. (1992), "Universals in the Content and Structure of Values: Theoretical Advances and Empirical Tests in 20 Countries," in Advances in Experimental Social Psychology, Elsevier, 1-65.

Scott, Maura L., Martin Mende, and Lisa E. Bolton (2013), "Judging the Book by Its Cover? How Consumers Decode Conspicuous Consumption Cues in Buyer-Seller Relationships," Journal of Marketing Research, 50(3), 334-347.

Tangney, June P., Roy F. Baumeister, and Angie Luzio Boone (2004), “High Self-Control Predicts Good Adjustment, Less Pathology, Better Grades, and Interpersonal Success," Journal of Personality, 72(2), 271-324.

Thaler, Richard H. and Hersh M. Shefrin (1981), "An Economic Theory of Self-Control," Journal of political Economy, 89(2), 392-406.

Thomas, Kyle A. and Scott Clifford (2017), "Validity and Mechanical Turk: An Assessment of Exclusion Methods and Interactive Experiments," Computers in Human Behavior, 77, 184-97.

Thurstone, Louis Leon (1947), "Multiple-Factor Analysis; a Development and Expansion of The Vectors of Mind." 
Turner, John C. (1991), Social Influence., Thomson Brooks/Cole Publishing Co.

Varnum, Michael EW (2013), "What Are Lay Theories of Social Class?,” PloS one, 8(7), e70589.

Veblen, Thorstein (1899), The Theory of the Leisure Class: An Economic Study in the Evolution of Institutions, Macmillan.

Vohs, Kathleen and Ronald Faber (2003), "Self-Regulation and Impulsive Spending Patterns," ACR North American Advances.

Wang, Yilin Andre and Paul Eastwick (2020), "Solutions to the Problems of Incremental Validity Testing in Relationship Science," https://psyarxiv.com/jm6xe/.

Watson, John J. (2003), “The Relationship of Materialism to Spending Tendencies, Saving, and Debt," Journal of economic psychology, 24(6), 723-739.

Weston, Sara J., Joe J. Gladstone, Eileen K. Graham, Daniel K. Mroczek, and David M. Condon (2019), "Who Are the Scrooges? Personality Predictors of Holiday Spending," Social psychological and personality science, 10(6), 775-782.

Wilson, Anne E. and Jaslyn A. English (2017), “The Motivated Fluidity of Lay Theories of Change," in The Science of Lay Theories, Springer, 17-43.

Wong, Alan and Bernardo J. Carducci (1991), "Sensation Seeking and Financial Risk Taking in Everyday Money Matters,” Journal of business and psychology, 5(4), 525-530.

Yeager, David S., Gregory M. Walton, Shannon T. Brady, Ezgi N. Akcinar, David Paunesku, Laura Keane, Donald Kamentz, Gretchen Ritter, Angela Lee Duckworth, and Robert Urstein (2016), "Teaching a Lay Theory before College Narrows Achievement Gaps at Scale," Proceedings of the National Academy of Sciences, 201524360. 
Table 1. Regression Analysis Predicting Lavish Spending from SIW Beliefs in Study 1

\begin{tabular}{clccc}
\hline & \multicolumn{4}{c}{ Model 1 } \\
& \multicolumn{3}{c}{ Proportion of Lavish Spending } \\
\hline Predictor & \multicolumn{1}{c}{$b$} & \multicolumn{3}{c}{ Cl $_{95 \%}$} \\
\hline SIW beliefs & $0.04^{*}$ & 2.45 & 0.01 & 0.08 \\
Age & $-0.02^{* * *}$ & -4.35 & -0.02 & -.01 \\
Male & $-0.17 \dagger$ & -1.81 & -0.35 & .01 \\
Income & $0.04^{*}$ & 2.01 & 0.001 & .08 \\
\hline
\end{tabular}

The analysis is a fractional logistic regression. $\mathrm{N}=2026$. The comparison group for Male is Female. A dummy variable representing missing gender information is omitted from the table. $\mathrm{b}=$ unstandardized regression coefficients. $\dagger p<.10, * p<.05, * * p<.01, * * * p<.001$ 
Table 2. Regression Models Predicting Financial Vulnerability from SIW Beliefs in Study 1

\begin{tabular}{|c|c|c|c|c|c|c|c|c|c|c|c|c|}
\hline \multirow{3}{*}{$\begin{array}{c}\text { Predictor } \\
\text { SIW beliefs }\end{array}$} & \multicolumn{4}{|c|}{$\begin{array}{c}\text { Model } 2 \\
\text { Amount Saved / Invested }\end{array}$} & \multicolumn{4}{|c|}{$\begin{array}{c}\text { Model } 3 \\
\text { Total Savings \& Investments }\end{array}$} & \multicolumn{4}{|c|}{$\begin{array}{c}\text { Model } 4 \\
\text { Financial Well-being Scale } \\
\end{array}$} \\
\hline & \multirow{2}{*}{$\frac{b}{-.11+}$} & \multirow{2}{*}{$\begin{array}{c}t \\
-1.77\end{array}$} & \multicolumn{2}{|c|}{$\mathrm{Cl}_{95 \%}$} & \multirow{2}{*}{$\frac{b}{-0.15^{\star}}$} & \multirow{2}{*}{$\begin{array}{c}z \\
-2.26\end{array}$} & \multicolumn{2}{|c|}{$\mathrm{Cl}_{95 \%}$} & \multirow{2}{*}{$\frac{b}{-.14^{\star * *}}$} & \multirow{2}{*}{$\frac{t}{-7.81}$} & \multicolumn{2}{|c|}{$\mathrm{Cl}_{95 \%}$} \\
\hline & & & -0.23 & 0.01 & & & -0.27 & -0.02 & & & -0.17 & -0.11 \\
\hline Age & .01 & 1.22 & -0.01 & 0.03 & $0.10^{* * *}$ & 12.15 & 0.08 & 0.12 & $-0.01^{* *}$ & 2.65 & -0.01 & -.001 \\
\hline Male & .20 & .70 & -0.37 & 0.77 & $1.05^{\star \star *}$ & 3.49 & 0.46 & 1.64 & -0.13 & 1.56 & 0.29 & 0.03 \\
\hline Income & $.29 * * *$ & 4.25 & 0.16 & 0.43 & $.62^{\star \star \star}$ & 9.18 & 0.49 & 0.75 & $.14^{* * *}$ & 7.62 & .11 & .18 \\
\hline
\end{tabular}

All models are OLS regression models. $\mathrm{N}=2026$. The comparison group for Male is Female. A dummy variable representing missing gender is omitted. $b=$ unstandardized regression coefficients. $* p<.05, * * p<.01, * * * p<.001$. 
Table 3. The Spending Implies Wealth (SIW) Belief Scale

\begin{tabular}{|c|c|c|c|c|}
\hline \# & Item & $M$ & $S D$ & $\begin{array}{c}\text { Item-rest } \\
r\end{array}$ \\
\hline 1 & Spending a lot indicates that someone is wealthy & 2.87 & 1.44 & .74 \\
\hline 2 & If someone isn't spending much money, they probably don't have much to spend & 3.26 & 1.53 & .78 \\
\hline 3 & Being wealthy indicates that someone will spend a lot & 2.97 & 1.46 & .66 \\
\hline 4 & I think people who spend more are wealthier than people who spend less & 3.43 & 1.58 & .71 \\
\hline 5 & $\begin{array}{l}\text { If you see someone who doesn't spend much money, you can be pretty sure that } \\
\text { they are not very wealthy }\end{array}$ & 2.62 & 1.33 & .76 \\
\hline 6 & Not spending money means you don't have much money to spend & 2.84 & 1.49 & .76 \\
\hline \multirow[t]{2}{*}{7} & People who spend less money than others probably don't have much to spend & 3.36 & 1.54 & .78 \\
\hline & Total & 3.05 & 1.10 & - \\
\hline
\end{tabular}


Table 4. Discriminant Validity Checks in Study 4

\begin{tabular}{|c|c|c|c|c|c|c|}
\hline Construct 1 & Construct 2 & $\begin{array}{c}\text { AVE of } \\
\text { construct } 1\end{array}$ & $\begin{array}{c}\text { AVE of } \\
\text { construct } 2\end{array}$ & $\begin{array}{c}\text { Correlation } \\
\text { between } \\
\text { constructs }\end{array}$ & $\begin{array}{l}\text { Squared } \\
\text { correlation }\end{array}$ & $\begin{array}{l}\text { Alpha for } \\
\text { construct } 2\end{array}$ \\
\hline SIW Scale & $\begin{array}{c}\text { MV } \\
\text { success }\end{array}$ & .61 & .49 & $0.17^{* \star *}$ & .06 & .74 \\
\hline SIW Scale & $\begin{array}{c}\text { MV } \\
\text { centrality }\end{array}$ & .61 & .42 & $0.09 \dagger$ & .01 & .67 \\
\hline SIW Scale & $\begin{array}{c}\text { MV } \\
\text { happiness }\end{array}$ & .61 & .64 & $.30^{\star \star \star}$ & .09 & .84 \\
\hline SIW Scale & MV overall & .61 & .40 & $.24^{\star \star *}$ & .06 & .86 \\
\hline SIW Scale & $\begin{array}{l}\text { Financial } \\
\text { literacy }\end{array}$ & .61 & .23 & -.08 & & .78 \\
\hline SIW Scale & Self-control & .61 & .29 & $-0.12^{*}$ & .02 & .84 \\
\hline
\end{tabular}

AVE refers to average variance extracted and was calculated using the results of a two-factor CFA model applied to all items from the two respective constructs. MV = material values. $\dagger p<.10, * p<.05, * * p<.01, * * * p<.001$ 
FIGURE 1

BINNED SCATTERPLOT OF FINANCIAL WELLBEING AND SIW BELIEFS

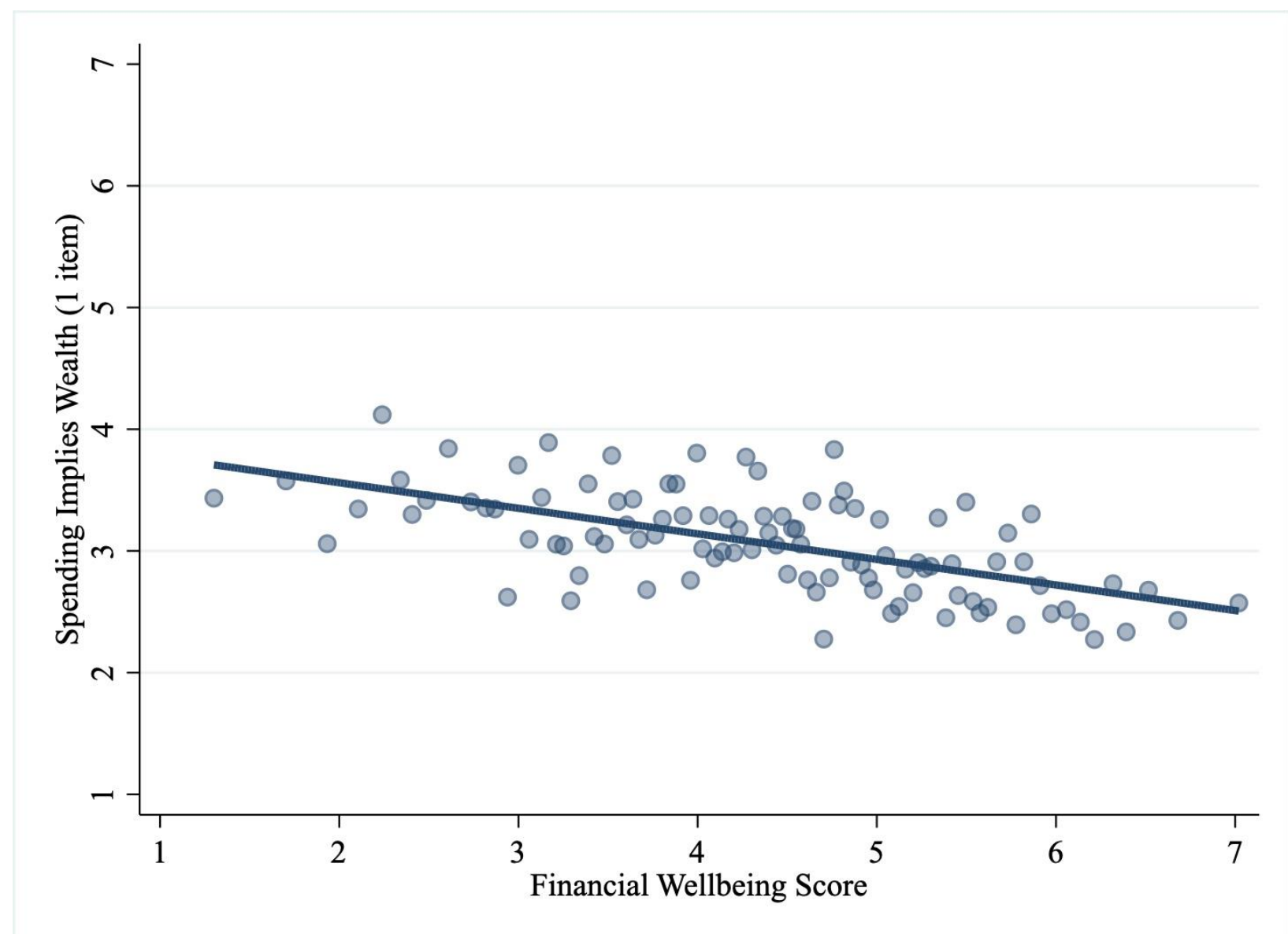

Note. Each circle represents the average SIW belief score for a given level of financial wellbeing, across 100 equally-sized bins of participants, holding age, income and gender constant. The binned scatterplot is overlaid with an OLS regression line. 
FIGURE 2

\section{AMOUNT ALLOCATED TO SPENDING CATEGORIES}

\section{BY EXPERIMENTAL CONDITION IN STUDY 2}

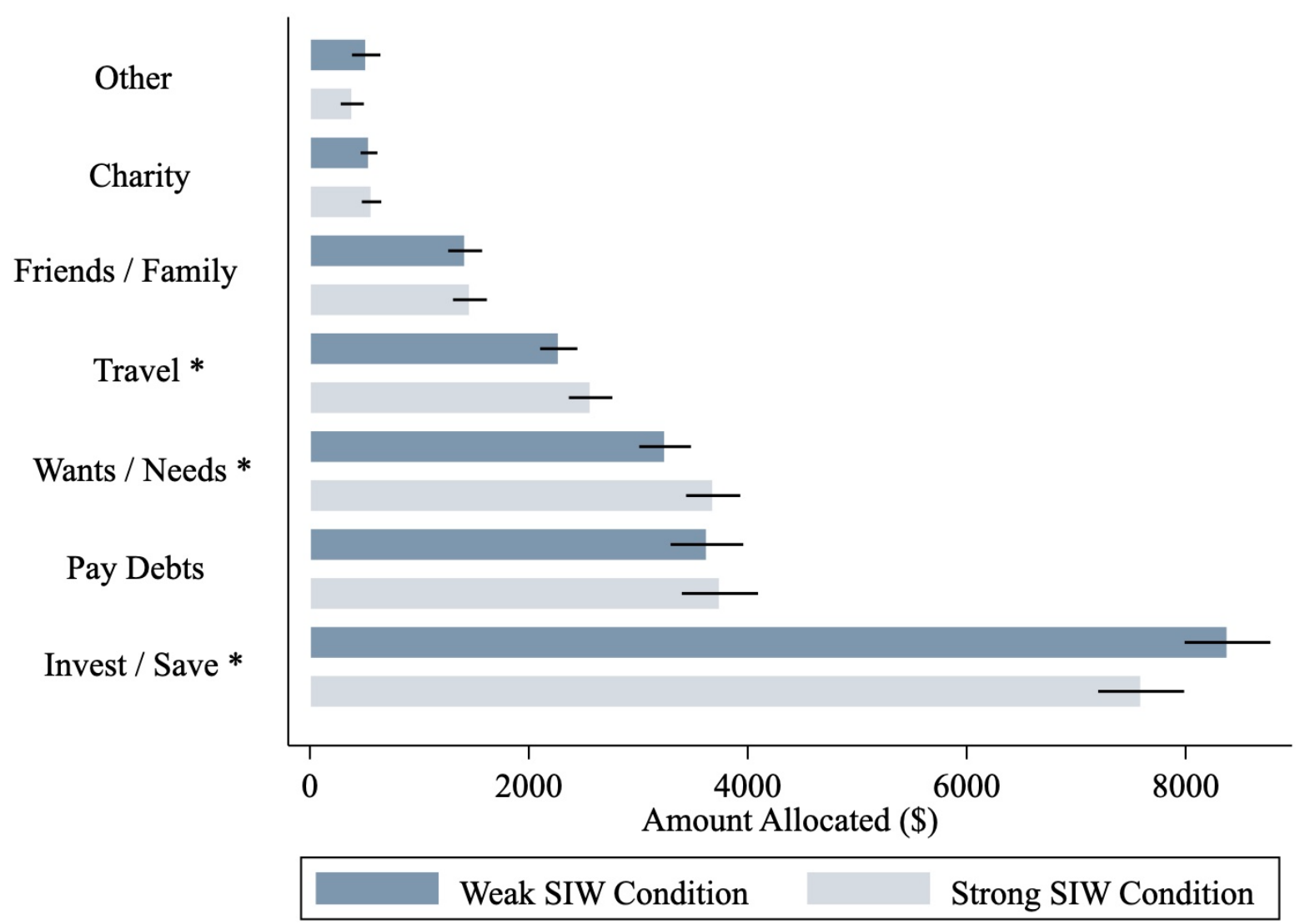

Note. Categories marked with a $*$ are $p<.05$ for the comparison between conditions. The categories Pay Debts and Invest / Save were combined as an indicator of frugal spending, per preregistration plan. Error bands are $95 \%$ confidence intervals. 
FIGURE 3

\section{KERNEL DENSITY PLOT ILLUSTRATING THE DISTRIBUTION OF SIW SCORES}

\section{IN STUDY 3}

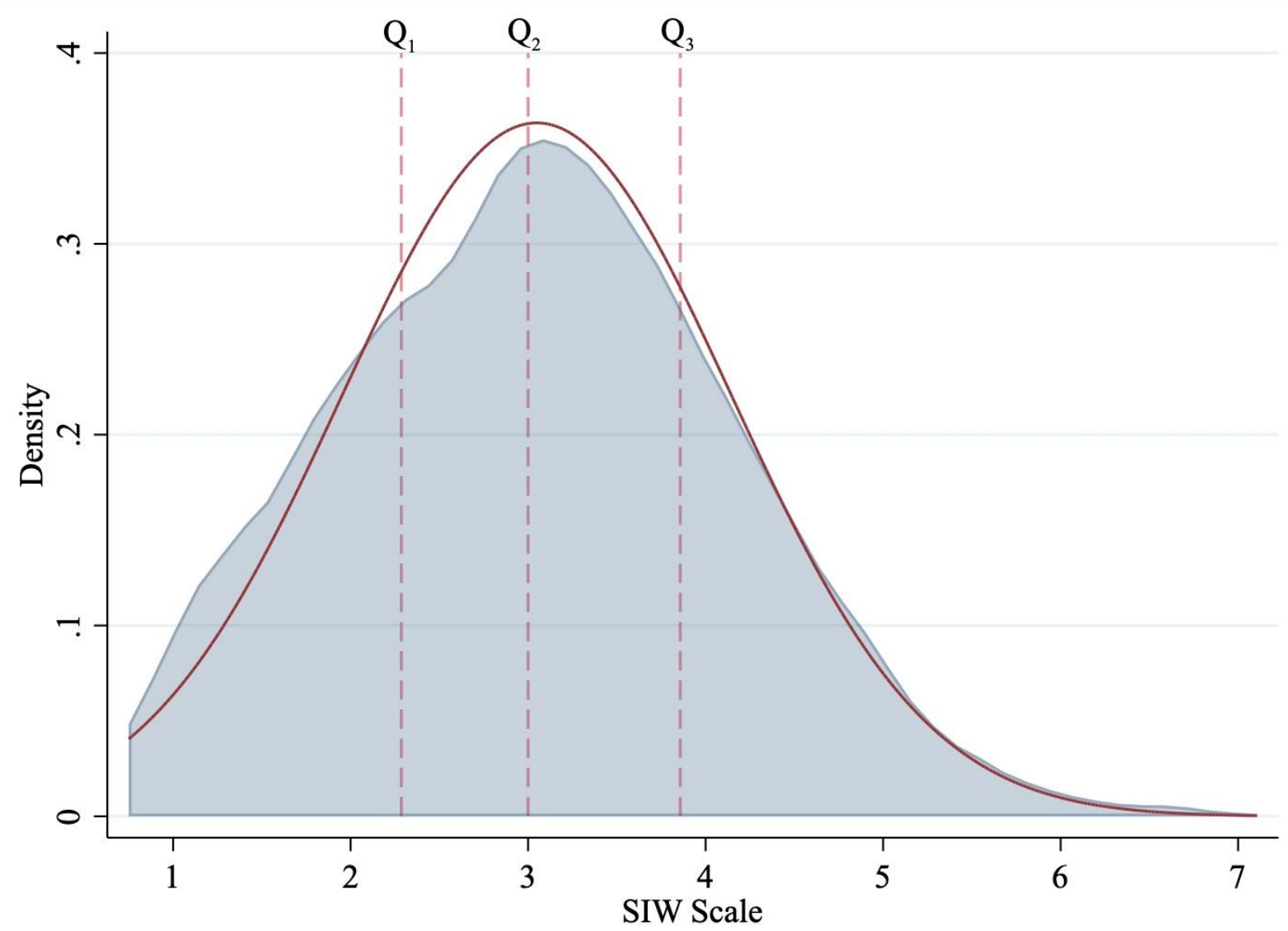

Note. $\mathrm{Q}=$ Quartile: dashed lines represent the $25^{\text {th }}\left(\mathrm{Q}_{1}\right), 50^{\text {th }}\left(\mathrm{Q}_{2}\right.$, the median $)$ and $75^{\text {th }}\left(\mathrm{Q}_{3}\right)$ percentiles. This means $25 \%$ of respondents have an SIW score below the $\mathrm{Q}_{1}$ line, and a further $25 \%$ score above the $\mathrm{Q}_{3}$ line. The density plot is overlaid with a solid line representing a normal distribution. 
FIGURE 4

PREDICTED SPENDING BY CATEGORY AS A FUNCTION OF SIW BELIEFS

IN STUDY 5

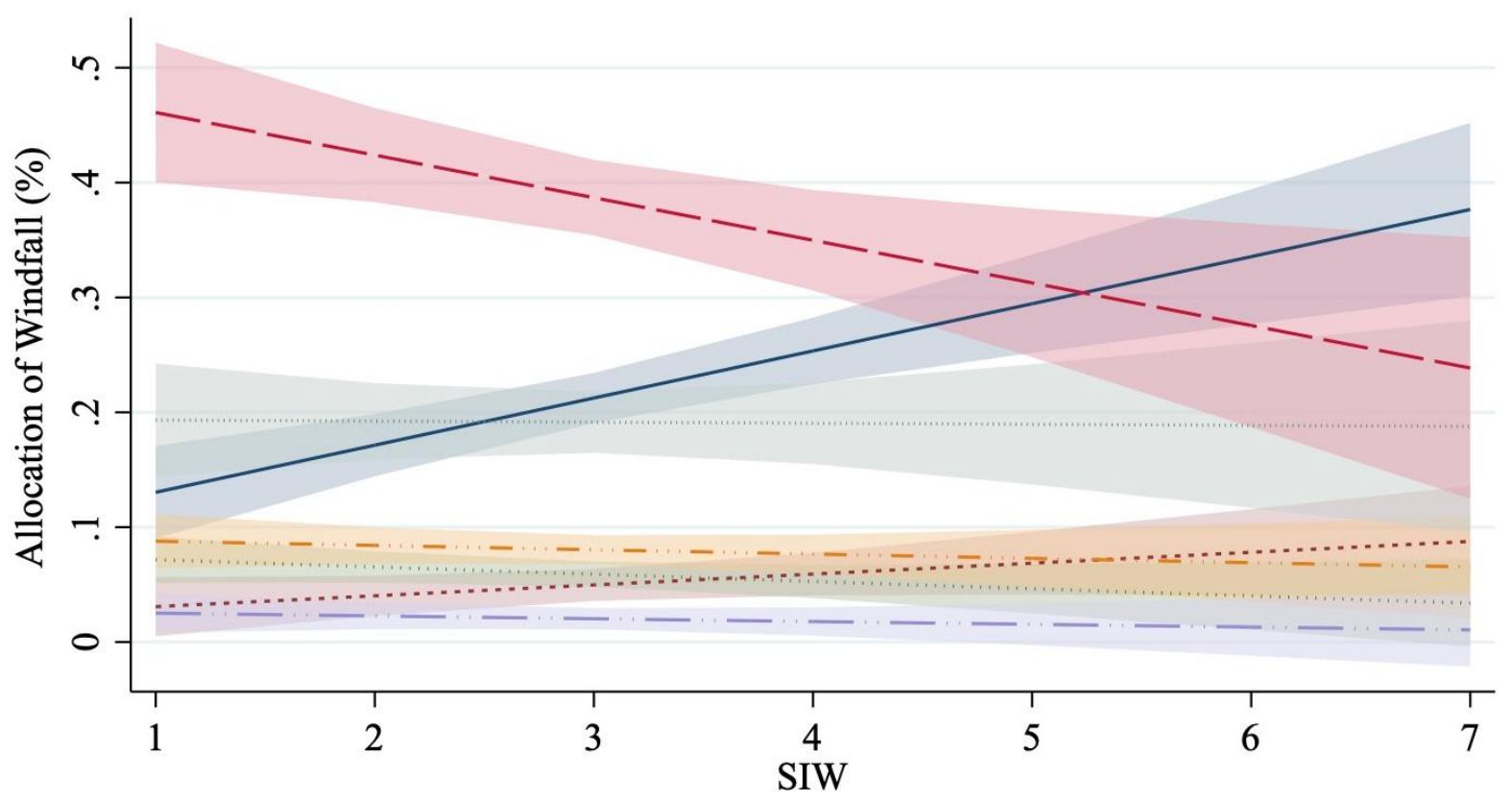

Spend on Wants / Needs Friends / Family

Charity and Church

Pay Down Debts

$-\cdots-\cdots-$ Travel

- - Other

-- Invest and Save 
FIGURE 5

PREDICTED IPAD BIDS ACROSS THE SIW SCALE BY EXPERIMENTAL CONDITION IN STUDY 6

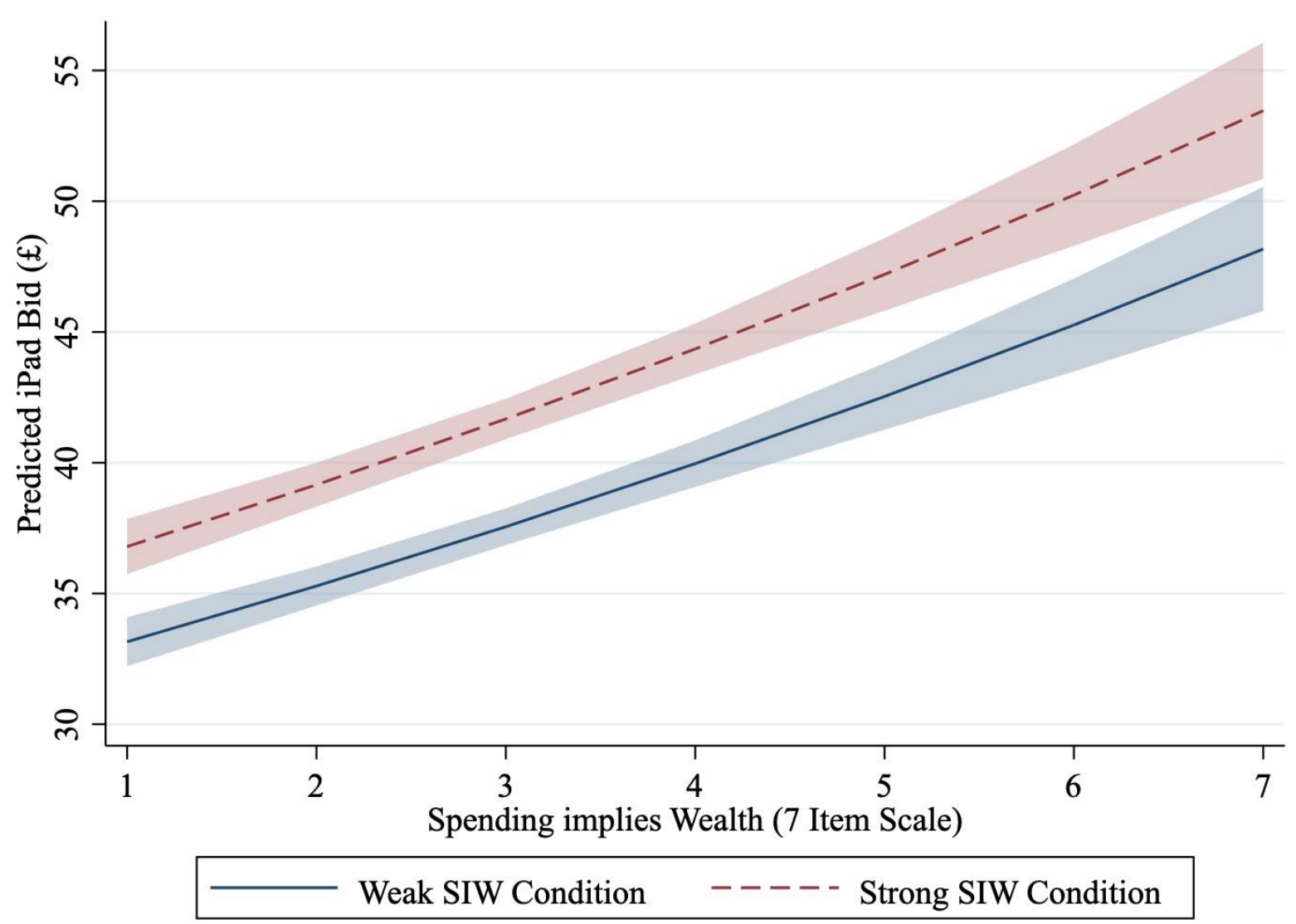

